\title{
Taxes versus quantities for a stock pollutant with endogenous abatement costs and asymmetric information
}

\author{
Larry Karp • Jiangfeng Zhang
}

Received: 12 September 2008 / Accepted: 10 August 2010 / Published online: 1 September 2010 C The Author(s) 2010. This article is published with open access at Springerlink.com

\begin{abstract}
We compare emissions taxes and quotas when a (strategic) regulator and (non-strategic) firms have asymmetric information about abatement costs, and all agents use Markov perfect decision rules. Firms make investment decisions that affect their future abatement costs. For general functional forms, firms' investment policy is information-constrained efficient when the regulator uses a quota, but not when the regulator uses an emissions tax. This advantage of quotas over emissions taxes has not previously been recognized. For a special functional form (linear-quadratic) both policies are constrained efficient. Using numerical methods, we find that a tax has some advantages in this case.
\end{abstract}

Keywords Pollution control · Investment · Asymmetric information · Rational expectations $\cdot$ Choice of instruments

JEL Classification $\quad \mathrm{C} 61 \cdot \mathrm{D} 8 \cdot \mathrm{H} 21 \cdot \mathrm{Q} 28 \cdot \mathrm{C} 72 \cdot \mathrm{H} 4 \cdot \mathrm{Q} 54$

Jiangfeng Zhang: The opinions expressed in this paper do not necessarily reflect the views of the Asian Development Bank.

We benefitted from comments by two anonymous referees. The usual disclaimer applies.

L. Karp ( $\varangle)$

Department of Agricultural and Resource Economics, University of California, Berkeley, USA

e-mail: karp@berkeley.edu

J. Zhang

Asian Development Bank, Manila, Philippines

e-mail: jzhang@adb.org 


\section{Introduction}

The danger that greenhouse gas (GHG) stocks cause environmental damage has led to a renewed interest in the problem of controlling emissions when there is asymmetric information about abatement costs. Although hybrid policies, e.g., cap and trade with a price ceiling, are more efficient than either the tax or quantity restriction (Pizer 1999), the comparison of taxes and quotas remains an important policy question. Since GHGs are a stock pollutant, the regulator's problem is dynamic. Most of the current literature on this dynamic problem assumes that non-strategic firms solve a succession of static problems. If, however, a firm's abatement costs depend on its stock of abatement capital, the firm makes a dynamic investment decision as well as the static emissions decision. We study the regulatory problem with asymmetric information when firms invest in abatement capital. We find that for general functional forms, quotas have an advantage over taxes that had not previously been recognized: quotas, but not taxes, are "information-constrained" optimal with respect to investment. We then consider a special functional form (linear-quadratic) where that advantage disappears, and here we find that taxes can increase abatement and welfare.

Earlier literature, e.g., Chichilnisky and Heal (1995), provided policymakers with the economic framework needed to compare different types of policies, thereby contributing to the creation of the carbon market currently used by some Kyoto signatories in the European Trading Scheme. Ellerman (2010) discusses the current state of this market. Our paper contributes to policy discussions by helping to illuminate a difference between taxes and quotas when forward-looking firms make investments that reduce abatement costs. In our setting, investment decreases costs by increasing the stock of abatement capital. We can also think of the firms' activity as investment in (excludable) R\&D.

For a variety of pollution problems, capital costs comprise a large part of total abatement costs (Vogan 1991) and investment in abatement capital depends on the regulatory environment. In these cases, the endogeneity of investment is an important aspect of the regulatory problem. Several recent papers (Buonanno et al. 2001; Goulder and Schneider 1999; Goulder and Mathai 2000; Norhaus 1999) assume that the regulator can choose emissions and also induce firms to provide the first-best level of investment, e.g., by means of an investment tax/subsidy.

We consider the situation where the regulator has a single policy instrument, either a sequence of emissions taxes or a sequence of quotas. This assumption is consistent with many regulations and proposals that involve an emissions policy but ignore endogenous investment (e.g., the Kyoto Protocol). In virtually any real-world problem, the regulator is likely to have fewer instruments than targets. Our model is an example of this general disparity between the number of instruments and targets, and therefore is empirically relevant. We identify a previously unrecognized difference between taxes and quantity restrictions, and we provide a simple means of solving the regulatory problem when a certain condition holds. ${ }^{1}$

\footnotetext{
1 Jaffe et al. (2003) and Requate (2005) survey the literature on pollution control and endogenous investment. Many papers in this literature, including Biglaiser et al. (1995), Gersbach and Glazer (1999), Kennedy and Laplante (1999), Montero (2002), Fischer et al. (2003), Moledina et al. (2003), and
} 
We now describe the problem in more detail. In each period, the representative firm observes an abatement cost shock that is private information. If this cost shock is serially correlated, the regulator learns something about its current value by observing past behavior. The firm knows the current value of the cost shock and therefore is better informed than the regulator. Both the regulator and firms obtain information over time. We examine a subgame perfect equilibrium in which the regulator and firms condition their decisions on "directly payoff-relevant" information, as distinct, for example from the entire history of actions. That is, we consider a Markov perfect equilibrium (MPE).

For the regulator, the payoff-relevant information consists of the aggregate stock of abatement capital (which affects the industry-wide marginal abatement costs), the stock of pollution (which determines marginal damages) and the regulator's beliefs about the current cost shock (which also affects the industry's marginal abatement costs). For the firms, the payoff-relevant information consists of the current policy level (the tax or quota), the current cost shock, the individual firm's level of abatement capital, the aggregate industry capital and the pollution stock. The last two state variables are payoff-relevant for the firm because the firm understands that these variables affect the evolution of aggregate capital stock and pollution stock, and the firm understands that the regulator conditions future policy levels on future values of those two stocks.

The assumption of Markov perfection means that the regulator cannot make binding commitments regarding future policies. Firms have rational expectations; they take the current emissions policy as given and they understand how the regulator chooses future policies. The non-atomic representative firm is not able to affect the economy-wide variables that determine future policies. The representative firm therefore behaves non-strategically, but not myopically, and also uses Markov policies.

The regulator understands that future emissions policies affect the current shadow value of abatement capital and thus affect current investment. For example, firms' anticipation that future emissions policies will be strict would increase the shadow value of abatement capital, thereby increasing the current level of investment. The regulator at the current time, $t$, might want to commit to a future policy, implemented at $t^{\prime}>t$, as a means of affecting current investment in abatement capital. This incentive is the source of the familiar time-consistency problem. After time $t$, the time- $t$ investment is predetermined, so the motivation for the time $t^{\prime}$ policy choice that was optimal at time $t$ has changed. Our setting has the usual ingredients that lead to this problem: the regulator with a second-best instrument (the emissions tax or quota) wants to influence forward-looking agents.

Subgame perfection is stronger than time-consistency; the former requires that no agent wants to deviate from the equilibrium strategy at any possible subgame, and the latter requires only that no agent wants to deviate from the equilibrium strategy at

\section{Footnote 1 continued}

Tarui and Polasky $(2005,2006)$ assume that firms behave strategically with respect to the regulator: firms believe that their investment decisions will affect future regulation. Several paper, including Malueg (1989), Milliman and Prince (1989), Requate (1998), Requate and Unold (2003) and Karp (2008) treat firms as non-strategic. Papers that discuss time-inconsistency arising because of the disparity between the number of targets and the number of instruments include Abrego and Perroni (2002) and Marsiliani and Renstrom (2002). 
subgames that actually occur in equilibrium. The assumption of Markov perfection (a refinement of subgame perfection) therefore implies time-consistency.

In order to understand an important difference between emissions taxes and quotas, it is useful to determine whether the restriction to time-consistency is a binding constraint. To this end, we ask whether the solution to the regulator's problem, in the absence of a time-consistency constraint, would in any case be time-consistent. If the private level of investment under the equilibrium emissions policy (the tax or quota) is socially optimal, then the regulator wants to use the emissions policy exclusively to influence emissions, without having to consider how the emissions policy affects investment. In this case, the regulator has no incentive to alter a previously announced policy rule. In this circumstance there is no time-consistency problem. Here we can obtain the MPE by solving an optimization problem that contains elements of the regulator's and the firms' problems. If, in contrast, firms' investment decisions are not socially optimal given beliefs about the emissions trajectory, then the regulator would like to choose the emissions policy partly to influence investment. In this case, the Markov perfect restriction, which implies time-consistency, actually constrains the regulator. Here, we need to solve an equilibrium problem (a dynamic game between the regulator and non-strategic firms) rather than a relatively simple dynamic optimization problem. In other words, the type of problem that we need to solve an equilibrium problem or an optimization problem depends on whether the equilibrium level of investment is socially optimal, conditional on the emissions trajectory.

There is another way of thinking about the time-consistency problem. The only market failure is that firms do not take into account the social damages arising from emissions. If there were no cost shock, or if the regulator and firms had symmetric information, either the emissions tax or the quota would be sufficient to induce firms to emit at the optimal level. In that case, firms' investment decisions would be first best. Therefore, if in addition to the emissions policy the regulator were able to use an investment tax, the optimal level of that tax would be identically zero. However, when there is asymmetric information about abatement costs, there is no assurance that either the emissions tax or the quota leads to the first best level of emissions. Therefore, with asymmetric information, the equilibrium level of investment under the emissions policy might not be (information-constrained) socially optimal. In that case, the optimal level of an investment tax would be non-zero.

We can ask our basic question in two equivalent ways. (1) Is the optimal emissions tax or quota policy time-consistent? (2) Would a regulator who uses either the emissions tax or the quota increase welfare by additionally using an investment tax/subsidy? (In other words: is the optimal investment tax/subsidy identically 0 ?).

We provide a simple answer to these questions. The optimal quota policy is timeconsistent; equivalently, when the regulator can use both an emissions quota and an investment tax, the latter is identically 0 . However, the optimal emissions tax policy is time-inconsistent, unless a particular " separability condition" holds; if this condition does not hold, the optimal investment tax, when used with the emissions tax, is not identically 0 .

This result is useful for two reasons. First, under plausible circumstances the separability condition does not hold. In these circumstances, an emissions tax cre- 
ates a secondary investment distortion, whereas the emissions quota does not. Thus, we have identified a difference between taxes and quotas that has previously been unnoticed.

Second, when the separability condition does hold, we can solve the dynamic game by solving a much simpler dynamic optimization problem that combines elements of the regulator's and the firms' optimization problems. The separability condition holds for an important special case, the linear-quadratic model, which has been previously used to study the problem of regulating both a flow and a stock pollutant under asymmetric information. Our separability result means that we can generalize the linear-quadratic model by including endogenous abatement capital. This generalization enables us to learn how the inclusion of endogenous abatement costs affects the ranking of the two policies. Our principal numerical finding is that, in the linearquadratic framework, including abatement costs increases the advantage of taxes over quotas.

In summary, explicit treatment of the investment decision renders the firms' decision problems dynamic. In general, this feature favors the use of quotas, because these, unlike taxes, introduce no distortion into firms' investment decisions. However, in special cases that include the linear-quadratic model, this distortion disappears with taxes. For our calibration, the explicit treatment of the investment decision favors taxes in the linear-quadratic setting.

The next section discusses a static problem that provides the intuition for the separability condition. Subsequent sections describe the dynamic model and show the role of the separability condition. We then discuss the linear-quadratic specialization, and explain how endogenous investment affects the comparison of taxes and quotas in that setting. In closing the paper, we discuss other aspects of the tax versus quantity debate, as it applies to climate change policy.

Other papers in this symposium discuss related aspects of the climate change problem. Asheim et al. (2011), Lauwers (2011), Figuieres and Tidball (2011) and Chichilnisky (2011) consider the ethical foundations of criteria for sustainability, and the possibility of implementing such programs. Lecocq and Hourcade (2011) examine the relation between income levels and abatement expenditure in an efficient solution. Dutta and Radner (2011) show that capital accumulation can exacerbate the tragedy of the commons, and that income transfers can alleviate this problem. Rezai et al. (2011) explain why meaningful climate policy may require smaller (or even zero) sacrifice by the current generation, contrary to the conclusions of mainstream integrated assessment models. Burniaux and Martins (2011) use a computable general equilibrium model to evaluate the key parameters in determining the magnitude of "carbon leakage". Ostrom (2011) emphasizes the importance of climate change policy at subglobal levels. Chipman and Tian (2011) elaborate on the role of the Coase Theorem in climate change policy.

\section{The one-period example}

This section uses a one-period model that demonstrates, in a simple setting, the difference between taxes and quotas when abatement costs are endogenous. We show that 
the emissions quota is always time-consistent; equivalently, if the regulator uses an emissions quota and also is able to use an investment tax/subsidy, the optimal investment tax is 0 . In contrast, the emissions tax is not time-consistent; equivalently, if the regulator uses an emissions tax and also is able to use an investment tax/subsidy, the investment tax is not 0 in general. However, the optimal emissions tax $i s$ time-consistent if and only if the primitive functions satisfy a particular "separability condition".

There is a simple explanation for this difference between taxes and quotas. An emissions policy chosen before investment has a " direct welfare effect" via its direct effect on emissions, and an "indirect welfare effect", via its effect on investment. When the policy level is chosen after investment, the regulator takes into account only the direct welfare effect, since investment is fixed. The optimality condition for the policy chosen before investment requires that the sum of the direct and the indirect welfare effects is set equal to 0 . The optimality condition for the policy chosen after investment requires that the direct welfare effect is set equal to 0 . These two optimality conditions are equivalent if and only if the indirect effect is 0 whenever the direct effect is 0 . That equivalence does not hold in general under taxes, but it does hold when the separability condition is satisfied. In contrast, the indirect welfare effect under quotas is always 0 , so the optimal quota is the same regardless of whether it is chosen before or after taxes. All of this becomes obvious once we develop some notation and write down the optimality conditions.

We normalize the initial level of abatement capital to 0 . The non-strategic but forward looking representative firm can buy $k$ units of abatement capital at cost $c(k)$; the firm obtains benefits $B(x, k, \theta)$ by emitting $x$ units of emissions when its stock of abatement capital is $k$ and the cost shock is $\theta$. We can think of the function $B(\cdot)$ as a restricted profit function in which input and output prices are suppressed. Alternatively, we can interpret $B(\cdot)$ as the amount of avoided abatement costs. For the latter interpretation, define $x^{b}$ as the Business-as-Usual (BAU) level of emissions, i.e., the level of emissions under the status quo. Define $a=x^{b}-x$ as the level of abatement, i.e., the reduction in emissions due to a new regulatory policy. The abatement costs associated with the new regulations are $A=A(k, \theta, a)$. If $x^{b}$ is a function of $(k, \theta)$, we can rewrite the abatement cost function as $A(k, \theta, a)=B(x, k, \theta)$, with $A_{a}(\cdot)=B_{x}(\cdot)$ : marginal abatement costs equal the marginal benefit of emissions.

The benefit function is increasing and concave in $x$ and $k$ and increasing in $\theta\left(B_{k}>\right.$ $\left.0, B_{\theta}>0, B_{x}>0, B_{k k}<0, B_{x x}<0\right)$. More abatement capital decreases the marginal cost of abatement and, therefore, lowers the marginal benefit of pollution, so $B_{x k}<0$. A higher cost shock increases the marginal benefits of abatement capital and emissions: $B_{k \theta} \geq 0, B_{x \theta} \geq 0$.

The damage from emissions (external to the firm) is $D(x)$. The regulator chooses either an emissions tax $p$ or an emissions quota $\bar{x}$. Throughout this paper, we assume that the emissions quota is binding for all realizations of $\theta$. Both the regulator and the firm have the same information about the distribution of $\theta$ before the firm observes its value.

Each firm has measure 0 , and by choice of units the mass of firms has measure 1. With this normalization, in a symmetric equilibrium $k$ and $x$ represent the industrywide capital stock and aggregate emissions, as well as the firm level values. The non-strategic firm chooses its (possibly constrained) level of $k$ and $x$ but takes the 
industry-wide levels as exogenous. In this section it is clear from the context whether we mean firm or aggregate level variables, but in a later section we modify the notation to avoid the possibility of misunderstanding.

We consider the following two time-lines:

Time Line A

1. The regulator chooses the policy level ( $p$ or $\bar{x})$.

2. The firm chooses investment $(k)$

\section{Nature reveals the cost shock $(\theta)$}

4. The firm makes its emissions decision $(x)$
Time Line B

1. The firm chooses investment $(k)$

2. The regulator chooses the policy level ( $p$ or $\bar{x})$.

3. Nature reveals the cost shock $(\theta)$.

4. The firm makes its emissions decision $(x)$.

With Time Line A, the emissions policy can influence both the levels of investment and emissions. With Time Line B, the emissions policy depends on the level of investment, and influences only the emissions level. In the one-period game, neither of the two time lines has a greater claim to plausibility, but the comparison of the two helps to understand the time-consistency problem in the dynamic setting.

If the optimal policy for the regulator is the same under both time lines, then it is obvious that the regulator uses that policy only to affect the emissions decision, not to influence the investment decision. In this case, the emissions policy does not create a secondary distortion in the investment decision; if we were to add a period after stage 2 and before stage 3 ("stage 2.5") to Time Line A, at which the regulator were permitted to revise the policy announced in stage 1 , the regulator would not want to make a revision when policies are time-consistent.

We show that the emissions quota is always time-consistent, but the emissions tax is time-consistent if and only if a particular separability condition holds. Equivalently, if we were to add a "stage 0" to either time line, at which the regulator announces an investment tax, the optimal investment tax is always 0 when the regulator uses an emissions quota, but it is 0 when the regulator uses an emissions tax if and only if the separability condition holds. To establish this claim, we examine each policy under both time lines.

Emissions taxes Under Time Line A, $p$ is predetermined when the individual firm chooses $k$. Under Time Line B, $p$ depends on aggregate capital, about which firms have rational point expectations. Since firms take aggregate capital as given when making their investment decision, and since they know the relation between $p$ and aggregate capital, it is "as if" they take $p$ as given under Time Line B as well. In short

Remark 1 Under both time lines, the individual firm takes $p$ as given when choosing its level of capital.

This remark simplifies comparison of the two time lines because we need only consider how the choice of time lines affects the regulator's strategic incentives; firms do not behave strategically, so the choice of time lines obviously does not affect their strategic incentives. 
Consider Time Line A when the regulator uses a tax. The representative firm's payoff in stage 2 is

$$
E[B(x, k, \theta)-p x-c(k)]
$$

where the expectation is with respect to $\theta$. The firm chooses $x$ in the last stage, conditional on $k, p$, and $\theta$. It chooses $k$ before it learns $\theta$. The first-order conditions for $x$ and $k$ and the corresponding decision rules (denoted using $*$ ) in stages 4 and 2 are

$$
\begin{array}{r}
B_{x}(x, k, \theta)-p=0 \Rightarrow x=x^{*}(k, p, \theta) . \\
E\left[B_{k}\left(x^{*}, k, \theta\right)-c^{\prime}(k)\right]=0 \Rightarrow k=k^{*}(p) .
\end{array}
$$

Note that $k^{*}(p)$ is independent of $\theta$. Differentiating the first-order condition (1) gives the comparative statics result

$$
\frac{\partial x^{*}}{\partial p}=\frac{-1}{B_{x x}(x, k, \theta)} \text { and } \quad \frac{\partial x^{*}}{\partial k}=\frac{-B_{x k}(x, k, \theta)}{B_{x x}(x, k, \theta)} .
$$

The regulator's problem under Time Line A is

$$
\max _{p} E\left[B\left(x^{*}, k^{*}, \theta\right)-c\left(k^{*}\right)-D\left(x^{*}\right)\right],
$$

leading to the first-order condition

$$
\begin{gathered}
E\left\{\left[B_{x}(*, \theta)-D^{\prime}\left(x^{*}\right)\right] \frac{\partial x^{*}}{\partial p}\right\}+E\left\{\left[\left[B_{x}(*, \theta)-D^{\prime}\left(x^{*}\right)\right] \frac{\partial x^{*}}{\partial k}\right.\right. \\
\left.\left.+B_{k}(*, \theta)-c^{\prime}\left(k^{*}\right)\right] \frac{\mathrm{d} k^{*}}{\mathrm{~d} p}\right\}=0,
\end{gathered}
$$

(using the notation $*=\left(x^{*}, k^{*}\right)$ ). Because $k^{*}(p)$ is independent of $\theta$, we can take $\frac{\mathrm{d} k^{*}}{\mathrm{~d} p}$ outside the expectations operator and use the firm's optimality condition (2) to write the regulator's optimality condition as

$$
E\left\{\left[B_{x}(*, \theta)-D^{\prime}\left(x^{*}\right)\right] \frac{\partial x^{*}}{\partial p}\right\}+\frac{\mathrm{d} k^{*}}{\mathrm{~d} p} E\left\{\left[B_{x}(*, \theta)-D^{\prime}\left(x^{*}\right)\right] \frac{\partial x^{*}}{\partial k}\right\}=0,
$$

The first term on the left side is the direct welfare effect of the tax and the second term is the indirect welfare effect, operating through investment.

The first-order condition for the firms' emissions decision is the same under the two time lines, since in both cases the firm conditions its emissions decision on predetermined values of $p$ and $k$ and the realized value of $\theta$. In view of Remark 1 , the first-order condition to the individual firm's investment problem under Time Line B is (apart from an inessential notational difference) still given by Eq. (2). This notational difference is that instead of treating $p$ as a predetermined variable, under Time Line $\mathrm{B}$ the firm treats $p$ as a function of aggregate capital, which the firm takes as given. 
The fact that (apart from the notational difference) the firm's first-order conditions are the same under the two time lines means that the functions $x^{*}(k, p, \theta)$, and $k^{*}(p)$ are also the same under the two time lines, although of course the values of $p$ in the two scenarios (therefore, the equilibrium values of $k$ and $x$ ) might differ. This possible difference is the key to the time-consistency issue. Under Time Line B, the regulator takes (aggregate) $k$ as given, so its first-order condition for the tax is

$$
E\left\{\left[B_{x}(*, \theta)-D^{\prime}\left(x^{*}\right)\right] \frac{\partial x^{*}}{\partial p}\right\}=0 .
$$

Note that this optimality condition equates the expected marginal benefits and costs of the tax, not the expected marginal benefits and costs of emissions. The two need not be the same, because in general $\frac{\partial x^{*}}{\partial p}$ depends on $\theta$.

Denote the optimal tax under Time Line B as $\hat{p}$. We assume that the regulator's problem is concave under both time lines, so that the solution to the respective firstorder condition is unique. Comparison of Eqs. (5) and (6) shows that the optimal emission tax is the same under the two time lines if and only if the indirect effect of the tax, evaluated at $p=\hat{p}$, is zero, i.e., if

$$
E\left\{\left[B_{x}(*, \theta)-D^{\prime}\left(x^{*}\right)\right] \frac{\partial x^{*}}{\partial k}\right\}_{\mid p=\hat{p}}=0 .
$$

We refer to the following as the "separability condition":

Condition 1 (Separability) $B_{x x}$ and $B_{x k}$, evaluated at the optimal $x^{*}$, are independent of $\theta$.

Remark 2 Equation (7) holds for all functions $B(x, k, \theta)$ if and only if the separability condition holds.

Proof In order to establish the sufficiency of Condition 1, note that it implies (using Eq. 3) that both $\frac{\partial x^{*}}{\partial p}$ and $\frac{\partial x^{*}}{\partial k}$ are independent of $\theta$. This independence, together with Eq. (6) and the fact that $\frac{\partial x^{*}}{\partial p} \neq 0$ imply that $\hat{p}$ (the optimal tax under Time line B) satisfies

$$
E\left[B_{x}\left(x^{*}\left(k^{*}, p, \theta\right), k^{*}, \theta\right)-D^{\prime}\left(x^{*}\left(k^{*}, p, \theta\right)\right)\right]=0 .
$$

That is, under Condition 1, the tax equates expected marginal benefits of emissions with marginal damages. The independence of $\frac{\partial x^{*}}{\partial k}$ and $\theta$, and the fact that $\frac{\partial x^{*}}{\partial k} \neq 0$, mean that Eq. (8) implies Eq. (7). Therefore, the optimal tax under the two lines is the same.

In order to establish necessity, note that if either $B_{x x}$ or $B_{x k}$ are not independent of $\theta$, it is straightforward to construct examples under which the regulator's first-order conditions for $p$ differ under the two time lines. 
It is also easy to show:

Remark 3 Suppose that the regulator uses an emissions tax. If we modify either time lines by adding a stage 0 at which the regulator is able to choose an investment tax/subsidy, the optimal level of this policy is identically 0 for all functions $B(x, k, \theta)$ if and only if the separability condition holds.

We omit the proof, which parallels the proof of Remark 2.

We see that time-consistency requires that Eq. (6) implies Eq. (7). Equation (6) states that the first-order change in welfare due to a change in the tax, (holding investment fixed), is zero. Equation (7) states that the first-order change in welfare due to a change in investment (holding the tax fixed) is zero. In general, of course, there is no reason that one equation implies the other, so in general the tax chosen before investment is not time-consistent. However, the separability condition implies two things about the problem: (1) $\frac{\partial x^{*}}{\partial p}$ is independent of $\theta$, so that setting the expected net marginal benefit of the tax (holding investment fixed) equal to 0 is equivalent to setting the expected net marginal benefit of emissions equal to 0 ; and (2) $\frac{\partial x^{*}}{\partial k}$ is independent of $\theta$, so that setting the expected net marginal benefit of investment (holding the tax fixed) equal to 0 is equivalent to setting the expected marginal benefit of emissions equal to 0 . When both Eqs. (6) and (7) are equivalent to setting expected net marginal benefit of emissions equal to 0 , the two are equivalent to each other.

Emissions quotas Based on the same reasoning that led to Remark 1, we have

Remark 4 Under both time lines, the individual firm takes the emissions quota as given when choosing its level of capital.

If the regulator uses quotas (that by assumption are binding for all $\theta$ ) the firm's emissions decision equals $\bar{x}$, and $\frac{\partial x^{*}}{\partial \bar{x}}=1$. In view of Remark 4 , the firm's first-order condition for the choice of $k$ (for both of the two time lines) is

$$
E\left[B_{k}(\bar{x}, k, \theta)-c^{\prime}(k)\right]=0 \Rightarrow k=k^{*}(\bar{x})
$$

As was the case with taxes, there is an unimportant notational issue: with Time Line $\mathrm{A}, \bar{x}$ is literally predetermined, while with Time Line $\mathrm{B}$, the firm treats $\bar{x}$ as a known function of aggregate investment, and the firm takes aggregate investment as given.

Under Time Line A, the regulator's first-order condition for $\bar{x}$ is

$$
\begin{gathered}
E\left\{\left[B_{x}\left(\bar{x}, k^{*}, \theta\right)-D^{\prime}(\bar{x})\right]+\left[B_{k}\left(\bar{x}, k^{*}, \theta\right)-c^{\prime}\left(k^{*}\right)\right] \frac{\mathrm{d} k^{*}}{\mathrm{~d} \bar{x}}\right\} \\
=E\left\{\left[B_{x}\left(\bar{x}, k^{*}, \theta\right)-D^{\prime}(\bar{x})\right]\right\}=0,
\end{gathered}
$$

where the first equality uses Eq. (9), the fact that $k^{*}$ is independent of $\theta$, and $\frac{d k^{*}}{d \bar{x}} \neq 0$. The first-order condition under Time Line B is identical to the second equality in Eq. (10). Thus, when non-strategic firms have rational expectations, the optimal quota is the same under the two time lines. The regulator uses the quota to target only emissions, and the firm's investment decision is information-constrained socially optimal. 
There is no social value in using an investment tax when the regulator uses an emissions quota.

The time-consistency of quotas is due to the fact that the indirect welfare effect of the quota is always 0 . Although the quota does affect the level of investment, the fact that the quota is always binding means that this investment does not affect the level of emissions. The only remaining indirect effect comes via the change in total cost; however, the private optimality of investment insures that it chosen so that expected marginal costs savings due to an extra unit of investment equals the marginal cost of investment. Thus, the private optimality of the investment decision insures that investment is also socially optimal.

\section{Basics of the dynamic model}

The stock of pollution at the beginning of period $t$ is $S_{t-1}$ and the flow of emissions in period $t$ is $x_{t}$. The fraction $0 \leq \Delta \leq 1$ of the pollution stock lasts into the next period, so the growth equation for $S_{t}$ is:

$$
S_{t}=\Delta S_{t-1}+x_{t}
$$

The period $t$ stock-related environmental damage equals $D_{t}=D\left(S_{t-1}\right)$, with $D^{\prime}>$ $0, D^{\prime \prime}>0$.

At time $t$ the representative firm's level of abatement capital is $K_{t-1}$ and its cost shock is $\theta_{t}$; when it emits at $x_{t}$ its benefit is $B_{t}=B\left(K_{t-1}, \theta_{t}, x_{t}\right)$. At time $t$ only the firm knows the value of the random cost shock $\theta_{t}$; there is persistent asymmetric information. All agents know the stochastic process for the cost shock, which we assume is $A R(1)$ :

$$
\theta_{t}=\rho \theta_{t-1}+\mu_{t}, \quad \mu_{t} \sim i i d\left(0, \sigma_{\mu}^{2}\right), \quad \forall t \geq 1
$$

with $-1<\rho<1 .^{2}$ The sequence $\left\{\mu_{t}\right\}(t \geq 1)$ is generated by an i.i.d. random process with zero mean and common variance $\sigma_{\mu}^{2}$. At time 0 the regulator knows $\theta_{-1}$, so the subjective expectation and variance of $\theta_{0}$ is $\left(\rho \theta_{-1}, \sigma_{\mu}^{2}\right)$. This assumption about the regulator's initial priors makes the problem stationary; it has no bearing on our results, but merely simplifies the notation. At time $t \geq 1$ the regulator's variance for the current shock is $\sigma_{\mu}^{2}$ provided that he has learned the value of the previous shock, $\theta_{t-1}$.

The representative firm invests in abatement capital to reduce future abatement costs, i.e., to increase future benefits from pollution. The flow of investment in period $t$ is $I_{t}$. The fraction of abatement capital that lasts into the next period is $0 \leq \delta \leq 1$, so the growth equation for $K_{t}$ is:

$$
K_{t}=\delta K_{t-1}+I_{t}
$$

\footnotetext{
2 Throughout the paper we refer to $\theta$ as a "cost shock", as an abbreviation for "random cost parameter". In most economically meaningful circumstances, this parameter is positively serially correlated: $\rho>0$.
} 
The cost of investment, $C_{t}=C\left(I_{t}, K_{t-1}\right)$, is increasing and convex in $I_{t}$. This convexity means that abatement capital does not adjust instantaneously.

The endogeneity of the investment decision means that the marginal abatement cost function, $B_{x}(\cdot)$, changes endogenously. Slower adjustment of abatement capital means that it is optimal to adjust emissions more slowly.

\section{The game}

In this section, it is helpful to distinguish between the representative firm's level of capital and the aggregate level of capital. We denote the former by $k$ and the latter by $k^{A}$. Where there is no danger of confusion, we denote both using $K$. Since we normalize the number of representative firms to $1, k^{A}=k=K$ in a symmetric equilibrium. The representative firm understands that it controls $k$, and that this variable affects its payoff directly, via the function $B(\cdot)$. This firm takes the aggregate level of capital $k^{A}$ as exogenous; $k^{A}$ has no direct effect on the firm's payoff. However, in a Markov perfect equilibrium, where the regulator conditions policies on payoff-relevant information, $k^{A}$ affects the firm's beliefs about future policies.

To avoid a proliferation of notation, we do not distinguish between the firm's level of emissions and the aggregate level of emissions. However, it is important to bear in mind that the firm treats aggregate emissions, and therefore, the aggregate pollution stock, as exogenous.

The regulator always uses taxes or always uses quotas. The period $t$ policy is the tax $p_{t}$ or the quota $x_{t}$. At time $t$ the regulator knows the aggregate capital stock $k_{t-1}^{A}$, the pollution stock $S_{t-1}$ and (as we explain below), the lagged cost shock $\theta_{t-1}$. These are the payoff-relevant variables for the regulator. In a Markov perfect rational expectations equilibrium, the representative firm takes the current level of the regulatory policy (at time $t$ ) as given; it understands that the policy at time $\tau>t$ will be a function of $\left(k_{\tau-1}^{A}, S_{\tau-1}, \theta_{\tau-1}\right)$. Since the firm takes these conditioning variables to be exogenous, it treats future policies as exogenous. This firm chooses investment $I_{t}$ under both policies, and it chooses the level of emissions if the regulator uses a tax.

In view of the timing conventions in the model, the regulator's current (tax or quota) policy influences the firm's current emission, but not the current level of investment. Investment depends on the firm's beliefs about future policies (as was the case with Time Line B in Sect. 2).

\subsection{The firm's emission and investment responses}

The firm wants to maximize the expectation of the present value of the stream of cost saving from polluting $(B)$ minus investment cost $(C)$ minus pollution tax payments (under taxes). The constant discount factor is $\beta$, and we use the superscripts $T$ and $Q$ to distinguish functions and variables under taxes and quotas.

Taxes. The firm's value function under taxes, $V^{T}\left(k_{t-1}, \theta_{t}, p_{t} ; S_{t-1}, k_{t-1}^{A}\right)$, solves the dynamic programming equation (DPE) 


$$
\begin{aligned}
V^{T}\left(k_{t-1}, \theta_{t}, p_{t} ; S_{t-1}, k_{t-1}^{A}\right)= & \max _{x_{t}, I_{t}}\left\{B\left(k_{t-1}, \theta_{t}, x_{t}\right)-p_{t} x_{t}-C\left(I_{t}, k_{t-1}\right)\right. \\
& \left.+\beta E_{t}\left[V^{T}\left(k_{t}, \theta_{t+1}, p_{t+1} ; S_{t}, k_{t}^{A}\right)\right]\right\}
\end{aligned}
$$

subject to the equation of motion for the cost shock (12), the capital stock (13), and the pollution stock (11). The firm's expectation at $t$ of $\theta_{t+1}$ and $p_{t+1}$ is conditioned on the payoff-relevant variables $\left(k_{t-1}^{A}, \theta_{t}, S_{t-1}\right)$.

The optimal level of emissions solves a static problem with the following first-order condition

$$
B_{x}\left(k_{t-1}, \theta_{t}, x_{t}\right)-p_{t}=0 .
$$

Solving for $x$, we obtain the optimal emission response

$$
x_{t}^{*}=\chi\left(k_{t-1}, \theta_{t}, p_{t}\right) \equiv \chi_{t} .
$$

The optimal level of investment equates the marginal cost of investment and the discounted shadow value of abatement capital. Setting $k^{A}=k=K$, the stochastic Euler equation is ${ }^{3}$

$$
\beta E_{t}\left\{B_{K}\left(K_{t}, \theta_{t+1}, \chi_{t+1}\right)-C_{K}\left(I_{t+1}, K_{t}\right)+\delta C_{I}\left(I_{t+1}, K_{t}\right)\right\}-C_{I}\left(I_{t}, K_{t-1}\right)=0 .
$$

This second-order difference equation has two boundary conditions, the current abatement capital $K_{t-1}$, and the transversality condition

$$
\lim _{T \rightarrow \infty} E_{t}\left\{\beta^{T-t} C_{I}\left(I_{T}, K_{T-1}\right) K_{T}\right\}=0 .
$$

Quotas Firms are homogeneous and quotas are not bankable. Thus, under a quota policy, there is no incentive to trade permits. The firm solves the DPE

$$
\begin{aligned}
V^{Q}\left(k_{t-1}, \theta_{t}, x_{t} ; S_{t-1}, k_{t-1}^{A}\right)= & \max _{I_{t}}\left\{B\left(k_{t-1}, \theta_{t}, x_{t}\right)-C\left(I_{t}, k_{t-1}\right)\right. \\
& \left.+\beta E_{t} V^{Q}\left(k_{t}, \theta_{t+1}, x_{t+1} ; S_{t}, k_{t}^{A}\right)\right\} .
\end{aligned}
$$

Again, the firm's beliefs about the quota in the next period depend on $\left(k_{t-1}^{A}, \theta_{t}, S_{t-1}\right)$.

\footnotetext{
3 For all of the control problems, we merely write the Euler equation since the derivations are standard. The first-order condition of the DPE with respect to $I_{t}$ provides one equation. In this first-order condition, the firm's expectation of $p_{t+1}$ is independent of its investment. This independence reflects the fact that the firm is unable to affect aggregate capital or pollution stock, and therefore cannot affect values of the variables that affect future regulation. We differentiate the DPE with respect to $k_{t-1}$, using the envelope theorem, to obtain a second equation. Combining these two equations gives the stochastic Euler equation.
} 
The optimal level of investment solves the stochastic Euler equation

$$
\beta E_{t}\left\{B_{K}\left(K_{t}, \theta_{t+1}, x_{t+1}\right)-C_{K}\left(I_{t+1}, K_{t}\right)+\delta C_{I}\left(I_{t+1}, K_{t}\right)\right\}-C_{I}\left(I_{t}, K_{t-1}\right)=0,
$$

and the transversality condition (17).

The investment rule Under both taxes and quotas, the current level of investment depends on the firm's beliefs about future policy levels, but it does not depend on the current policy level. The firm has rational expectations about future policies; we discuss this policy rule in the next section. Under either taxes or quotas, the representative firm's equilibrium investment rule at time $t$ is a function of $\left(k_{t-1}, \theta_{t} ; S_{t-1}, k_{t-1}^{A}\right)$. When there is no danger of confusion, we write the investment rule as $I^{j}\left(K_{t-1}, \theta_{t}, S_{t-1}\right), j=T, Q$ (for tax or quota).

\subsection{The regulator's problem}

The regulator's payoff equals the payoff to the representative firm net of taxes, minus environmental damages. The regulator maximizes the expectation of the present discounted value of the flow of the payoff, i.e., the expectation of

$$
\sum_{t=0}^{\infty} \beta^{t}\left(B\left(K_{t-1}, \theta_{t}, x_{t}\right)-C\left(I_{t}, K_{t-1}\right)-D\left(S_{t-1}\right)\right) .
$$

His policy (always a tax or always a quota) can be a function of (only) payoff-relevant variables: the current stocks of pollution and capital, and the regulator's current information about the cost shock. Under taxes the regulator knows that Eq. (15) determines emissions. Under either policy, he knows that investment is given by $I^{j}\left(K_{t-1}, \theta_{t}, S_{t-1}\right), j=T, Q$.

The regulator takes as given the investment rule and (under taxes) the emissions rule. At time $t$ the regulator observes the aggregate stocks $S_{t-1}, K_{t-1}$. If $\rho=0$, the regulator learns nothing about the current cost shock by observing firms' past behavior. The past cost shock provides information about the current shock if and only if $\rho \neq 0$. Under taxes, the regulator learns the previous cost by observing the response to the previous tax (via Eq. 15). With tradable quotas, the regulator learns the previous cost by observing the previous quota price. ${ }^{4}$

The regulator's decision rule is a function $z^{j}\left(K_{t-1}, \theta_{t-1}, S_{t-1}\right), j=T, Q$ that determines the current tax $(j=T)$ or quota $(j=Q)$ as a function of his current information, given his beliefs about the firm's decision rules.

\footnotetext{
4 Under either policy, the regulator can also learn the previous cost shock by observing lagged investment, provided that $B_{K \theta} \neq 0$. From Eq. (18), $B_{K \theta} \neq 0$ means that current investment depends on the firm's beliefs about future cost shocks. When $\rho \neq 0$ these beliefs_-and therefore current investment—depend on the current cost shock.
} 


\subsection{The equilibrium}

Both the regulator and the representative firm solve stochastic control problems; the exact problem that one agent solves depends on the solution to the other agent's problem. The rational expectations equilibrium investment rule for the firm depends on the regulator's policy rule, and that policy rule depends on the equilibrium investment rule. The investment and the regulatory decision rules generate a random sequence of pollution and capital stocks. Agents have rational expectations about these random variables.

An equilibrium consists of a (possibly non-unique) pair of decision rules $I^{j *}\left(K_{t-1}, \theta_{t}, S_{t-1}\right)$ and $z^{j *}\left(K_{t-1}, \theta_{t-1}, S_{t-1}\right)$ for $j=T, Q$ that are mutually consistent; the superscript “ $*$ ” indicates equilibrium functions. Hereafter, we refer to $I^{j *}\left(K_{t-1}, \theta_{t}, S_{t-1}\right)$, and $z^{i *}\left(K_{t-1}, \theta_{t-1}, S_{t-1}\right)$ as Markov perfect policy rules.

Modern computational methods make it possible to (approximately) solve these kinds of dynamic equilibrium problems, i.e., to find a fixed point in function space (Judd 1998; Marcet and Marimon 1998; Miranda and Fackler 2002). These fixed point problems are not trivial, especially when the state space has more than one dimension-it has three in our problem.

\section{Finding the Markov perfect equilibrium}

In many cases, the type of model described in the previous section must be solved as an equilibrium problem rather than as an optimization problem. The next subsection explains why this complication might arise. Using an auxiliary control problem in which the regulator has two policy instruments, we then identify conditions under which the model can be solved as a straightforward optimization problem.

\subsection{The time-consistency problem}

In general, the regulator might want to announce a rule that would determine future levels of the tax or quota. The purpose of such an announcement would be to alter the firm's investment rule_-as distinct from altering a stock that appears as an argument of the investment rule. The inability to make binding commitments, and the Markov assumption, exclude this possibility. In a rational expectations equilibrium, current investment depends on beliefs about future policies, and these beliefs and policies depend on the pollution stock. By choice of the current quota or tax level, the regulator affects the future pollution stock, which can affect future investment. Under our assumptions, the only means by which this period'spolicy can influence future investment is by influencing the future level of the pollution stock.

Consider a simpler problem without asymmetric information, where a representative firm with rational expectations makes investment decisions. The firm's optimal decisions depend on its beliefs about future regulations, and the regulator wants to influence the firm's decisions. If the regulator has a first best policy (defined as one that does not cause secondary distortions), he can induce the firm to select exactly the decisions that the regulator would have used, had he been in a position to choose 
them directly. In that case, the regulatory problem can be solved as standard optimization problem. If, however, the regulator has only a second-best policy, the familiar time-consistency problem arises. (See Xie 1997; Karp and Lee 2003 for discussions of this problem, and references.) The Markov restriction is binding in this setting, so finding the equilibrium requires solving an equilibrium problem rather than a standard optimization problem.

The presence of asymmetric information in our model leads to the possibility of time-inconsistency of the optimal emissions tax or quota. We know from the literature on principal-agent problems that with asymmetric information, non-linear policies are generally superior to either the linear tax or the quota. We noted in Sect. 4.1 that the firm's investment depends on its beliefs about future policies. Since the regulator has two targets, (emissions and investment) and only one instrument, it appears that the regulator might want to use future emissions taxes or quotas to influence the firm's current investment decision. In that case, the information-constrained first best tax or quota would be time-inconsistent: the ability to make commitments about future taxes or quota decision rules would enable the regulator to achieve a higher payoff than under the Markov restriction. If this were the case, we would not be able to obtain a Markov perfect equilibrium merely by solving a dynamic optimization problem, but would instead have to solve the equilibrium problem described in the previous section.

\subsection{An auxiliary control problem}

This subsection describes an auxiliary control problem that helps identify conditions under which the Markov perfect equilibrium can be obtained by solving an optimization problem. In this auxiliary control problem, in each period the regulator sets an emissions tax or quota using the same information as in the game; later in the same period he observes the current cost shock and then chooses investment directly. In contrast, in the game the regulator chooses only an emissions policy. The regulator's ability (in the auxiliary problem) to control current investment directly, knowing the current cost shock, eliminates any incentive to use future emissions policies to control current investment.

In this setting, it does not matter whether the regulator chooses investment directly (e.g., by command and control), or decentralizes this decision by means of an investment tax/subsidy. In the former case, firms make no investment decision, and in the latter case, firms merely carry out the optimal investment decision induced by the investment tax/subsidy. However, the model with the investment tax/subsidy is more helpful with intuition, so we emphasize that model. The optimal investment tax/subsidy is identically 0 if and only if Markov perfect rules in the game are equivalent to the optimal policy rules in the auxiliary problem. With an identically zero investment tax, agents in the auxiliary problem have exactly the same optimization problem as in the game. It is optimal to use a non-zero investment tax/subsidy if and only if the Markov perfect policies do not solve the auxiliary problem.

In the auxiliary problem, we need to consider a two-stage optimization within each period. At the beginning of the period the regulator knows $\left(K_{t-1}, \theta_{t-1}, S_{t-1}\right)$ and 
chooses the emissions policy (a tax or quota); the regulator then learns $\theta_{t}$ and chooses the level of investment or the investment tax/subsidy. It does not matter whether this time-line is plausible. We use this problem only as a means of finding conditions under which the Markov perfect rules can be obtained by solving a control problem.

Suppose we find that the investment tax/subsidy is identically 0 in the auxiliary control problem. In this case, the regulator is willing to allow firms to choose investment, given that the regulator chooses the emissions policy. The regulator in the game is therefore also willing to allow firms to choose investment. That is, the regulator in the game also has no wish to use an investment tax/subsidy.

\subsubsection{Quotas in the auxiliary problem}

When the regulator chooses emissions quotas in the auxiliary problem he solves the following DPE:

$$
\begin{aligned}
\mathcal{J}^{Q}\left(K_{t-1}, S_{t-1}, \theta_{t-1}\right)= & \max _{x_{t}} E_{\theta_{t} \mid \theta_{t-1}}\left\{B\left(K_{t-1}, \theta_{t}, x_{t}\right)-D\left(S_{t-1}\right)\right. \\
& \left.+\max _{I_{t}}\left[-C\left(I_{t}, K_{t-1}\right)+\beta \mathcal{J}^{Q}\left(K_{t}, S_{t}, \theta_{t}\right)\right]\right\}
\end{aligned}
$$

subject to Eqs. (11) and (13). The first-order condition for the optimal quota is

$$
E_{\theta_{t} \mid \theta_{t-1}}\left\{B_{x}\left(K_{t-1}, \theta_{t}, x_{t}\right)+\beta \mathcal{J}_{S}^{Q}\left(K_{t}, S_{t}, \theta_{t}\right)\right\}=0
$$

and the Euler equation for investment under quotas is

$$
\begin{aligned}
& \beta E_{\theta_{t+1} \mid \theta_{t}}\left\{B_{K}\left(K_{t}, \theta_{t+1}, x_{t+1}\right)-C_{K}\left(I_{t+1}, K_{t}\right)+\delta C_{I}\left(I_{t+1}, K_{t}\right)\right\} \\
& \quad-C_{I}\left(I_{t}, K_{t-1}\right)=0 .
\end{aligned}
$$

The transversality condition is

$$
\lim _{T \rightarrow \infty} E_{\theta_{T} \mid \theta_{t}}\left\{\beta^{T-t} C_{I}\left(I_{T}, K_{T-1}\right) K_{T}\right\}=0
$$

\subsubsection{Taxes in the auxiliary problem}

Using the firm's emission response function (15), the regulator in the auxiliary problem with emissions taxes solves the following DPE

$$
\begin{aligned}
\mathcal{J}^{T}\left(K_{t-1}, S_{t-1}, \theta_{t-1}\right)= & \max _{p_{t}} E_{\theta_{t} \mid \theta_{t-1}}\left\{B\left(K_{t-1}, \theta_{t}, x_{t}^{*}\right)-D\left(S_{t-1}\right)\right. \\
& \left.+\max _{I_{t}}\left[-C\left(I_{t}, K_{t-1}\right)+\beta \mathcal{J}^{T}\left(K_{t}, S_{t}, \theta_{t}\right)\right]\right\}
\end{aligned}
$$


subject to Eqs. (11), (13) and (15). We use the definition

$$
H_{t} \equiv\left[B_{x}\left(K_{t-1}, \theta_{t}, x_{t}^{*}\right)+\beta \mathcal{J}_{S}^{T}\left(K_{t}, S_{t}, \theta_{t}\right)\right],
$$

and the abbreviation $\chi_{t} \equiv \chi\left(K_{t-1}, \theta_{t}, p_{t}\right)=x_{t}^{*}$. The function $H_{t}$ is the social benefit of an additional unit of emissions, and recall that $\chi$ is the firm's decision rule for emissions under emissions taxes (Eq. 15). With this notation, we can write the first-order condition with respect to $p_{t}$ as

$$
E_{\theta_{t} \mid \theta_{t-1}}\left\{H_{t} \frac{\partial \chi_{t}}{\partial p_{t}}\right\}=0
$$

and the stochastic Euler equation for investment as

$$
\begin{aligned}
& \beta E_{\theta_{t+1} \mid \theta_{t}}\left\{B_{K}\left(K_{t}, \theta_{t+1}, x_{t+1}^{*}\right)-C_{K}\left(I_{t+1}, K_{t}\right)+\delta C_{I}\left(I_{t+1}, K_{t}\right)+H_{t+1} \frac{\partial \chi_{t+1}}{\partial K_{t}}\right\} \\
& -C_{I}\left(I_{t}, K_{t-1}\right)=0 .
\end{aligned}
$$

The transversality condition is Eq. (22).

5.3 Social optimality of the Markov perfect rules

Differentiating the first-order condition (14) implies the following:

Lemma 1 Condition 1 is equivalent to the following two conditions: (1) $\frac{\partial \chi\left(K_{t-1}, \theta_{t}, p_{t}\right)}{\partial p_{t}}$ is independent of $\theta_{t}$, (2) $\frac{\partial \chi\left(K_{t-1}, \theta_{t}, p_{t}\right)}{\partial K_{t-1}}$ is independent of $\theta_{t}$, where $p_{t}$ is the time $t$ emissions tax.

Our main result is the following:

Proposition 1 (i) When the regulator uses emissions quotas, the solution to the auxiliary problem (19) is a Markov perfect equilibrium to the original game. (ii) When the regulator uses emissions taxes, the solution to the auxiliary problem (23) is a Markov perfect equilibrium to the original game if and only if the separability condition holds.

The proof, contained in Appendix 1, verifies that the equilibrium conditions in the games and in the auxiliary problems are identical under the conditions stated in the proposition.

\subsubsection{Significance of the proposition}

When the regulator uses quotas to control emissions, the Markov perfect investment rule is always information-constrained socially optimal. With emissions quotas, the ability to use an additional policy instrument to influence investment does not increase social welfare. 
If the regulator uses emissions taxes to control emissions, the Markov perfect investment rule is socially optimal if and only if Condition 1 is satisfied. This condition depends only on the benefit function $B(\cdot)$, not on the damage or the investment cost function. If the separability condition holds, the investment tax that supports optimal investment in the auxiliary problem is identically 0 .

Proposition 1 identifies a previously unnoticed difference between taxes and quotas. When the separability condition does not hold, the regulator who uses an emissions tax to control pollution creates a secondary distortion in investment. In these circumstances, private investment is optimal under an emissions quota but not under an emissions tax. The emissions tax, but not the quota, creates the need for an investment tax/subsidy.

The proposition also provides a simple way of obtaining the equilibrium for the game when the separability condition holds. This method requires only solving a dynamic optimization problem rather than a dynamic equilibrium problem.

\subsubsection{Interpretation of the separability condition}

We first identify the secondary distortion under emissions taxes, and we explain why it vanishes if the separability condition holds. This discussion also explains why emissions taxes and quotas typically have different effects, as regards the secondary distortion.

In order to identify the secondary distortion, we follow the standard procedure of computing the investment tax/subsidy that supports the information-constrained first best investment policy. Suppose that firms face an investment tax $s_{t}$, so their single period payoff is $B(\cdot)-C(\cdot)-s_{t} I_{t}-p_{t} x_{t}$. We can write the Euler equation for the capital stock corresponding to this problem, and compare it to the optimal investment policy under an emissions tax, Eq. (25). We omit the details, but the comparison implies that the investment tax supports the socially optimal level of investment if and only if ${ }^{5}$

$$
-s_{t}+\beta \delta E_{\theta_{t+1} \mid \theta_{t}} s_{t+1}=\beta E_{\theta_{t+1} \mid \theta_{t}}\left\{H_{t+1} \frac{\partial \chi_{t+1}}{\partial K_{t}}\right\} .
$$

The left side of Eq. (26) equals the effect of the tax sequence on the marginal incentive to invest in the current period. Under the investment tax, an additional unit of investment costs the firm $s_{t}$ in the current period, but reduces the expected cost of tax payments by $\delta E_{t} s_{t+1}$ in the next period. The right side of Eq. (26) is the present value of the expectation of the secondary distortion. $H_{t+1}$ is the marginal value to society of an additional unit of emissions in the next period, and $\frac{\partial \chi_{t+1}}{\partial K_{t}}$ equals the change in emissions in the next period caused by an additional unit of investment in the current period. Thus, the term in brackets in Eq. (26) is the value to society of the lower future emissions caused by the additional investment. This benefit is external to the firm. The optimal investment tax sequence induces the firm to internalize the present value of

\footnotetext{
5 The right side of Eq. (26) equals the function $\tau$, used in the proof of Proposition 1.
} 
the expectation of this additional social benefit of investment, i.e., to internalize the externality.

The optimal emission quota does not create a secondary distortion. Under the quota, the expected social benefit of an additional unit of emissions is zero in each period (Eq. 20). The socially optimal rule for determining investment, Eq. (21), involves only the current and future expected marginal investment and abatement costs. The socially optimal balance of these costs is identical to the balance that firms choose.

The optimal emissions tax, in contrast, requires that a marginal change in the tax has zero expected social value (Eq. 24). This condition is not, in general, equivalent to the requirement that the expected social marginal benefit of emissions $\left(H_{t}\right)$ is zero. The expected social marginal benefit of an additional unit of emissions is zero if and only if $B_{x x}$ is independent of $\theta$ (equivalently, if and only if $\frac{\partial \chi}{\partial p}$ is independent of $\theta$ ). This independence implies that $E_{t} H_{t}=0$.

Even if this independence holds, $H_{t}$ is a random variable, a function of $\theta$. If $\frac{\partial \chi}{\partial K}$ is also a function of $\theta$ (i.e., if $B_{x K}$ is not independent of $\theta$ ), then the social marginal benefit of emissions is correlated with $\frac{\partial \chi}{\partial K}$. In that case, the expected marginal value to society of the lower future emissions caused by the additional investment (i.e., the secondary distortion, measured by the right side of Eq. (26) is non-zero. Here, the investment externality is non-zero. Consequently, both $B_{x x}$ and $B_{x K}$ must be independent of $\theta$ in order for the investment externality to vanish under emissions taxes.

\section{The linear-quadratic model}

The static model with a flow pollutant shows that a simple comparison of taxes and quotas requires strong functional assumptions: quadratic abatement costs and quadratic damages and additive uncertainty (the "linear-quadratic model") (Weitzman 1974). Without these assumptions, the ranking of taxes and quotas depends on parameters such as the variance of the cost uncertainty, for which we have very poor (if any) estimates. The major insight from the static linear-quadratic model is that taxes dominate quotas when the marginal abatement cost function is steeper than the marginal environmental damage function.

Analytical comparisons of the two policies in the climate change literature use the linear-quadratic model in which damages arise from the pollution stock, rather than the flow of emissions. Some commentators have claimed that for the regulation of GHGs, taxes obviously dominate quotas, because the marginal damage function for GHGs is so flat relative to the marginal abatement cost function. This reasoning is faulty, because in the dynamic setting the marginal abatement cost depends on the flow of emissions, while the marginal damage depends on the stock of pollution. The two slopes have different units in the dynamic problem, whereas they have the same units in the static problem. ${ }^{6}$ In the dynamic setting it is not sensible to simply compare

\footnotetext{
6 Suppose we measure stock $S$ in tonnes and emissions $x$ in tonnes/year. Suppose that single period environmental damage is $a+b S^{2}$ and abatement cost is $c+d x^{2}$ and both are measured in dollars per year. Then the units of $b$, the slope of marginal damages, are $\frac{\$}{\text { year.(tonne) })^{2}}$ and the units of $d$, the slope of marginal abatement costs, are $\frac{\$ \cdot \text { year }}{(\text { tonne })^{2}}$.
} 
magnitudes of the two slopes. The dynamic optimization problem has to be solved in order to know how to compare these slopes, i.e., to know what constitutes a "large slope" and a "small slope" with GHGs.

This analysis has been undertaken with the competing assumptions that the regulator announces the entire sequence of future policies today (the open loop assumption) (Newell and Pizer 2003) or that the regulator conditions future policies on future information (the feedback assumption) (Hoel and Karp 2002; Karp and Zhang 2005), and under the assumption that the regulator expects to learn about a damage parameter (Karp and Zhang 2006). This analysis, together with available estimates of parameter values, supports the view that taxes dominate quotas for climate policy. Numerical results that do not use the linear-quadratic model also support this conclusion (Pizer 1999; Hoel and Karp 2001; Pizer 2002).

To determine the effect of endogenous abatement capital, it makes sense to use the linear-quadratic model. This functional form allows us to compare our results with those of earlier papers in this literature. With different functional assumptions, we would not be able to isolate the effect of endogenous capital. The linear-quadratic model satisfies the separability assumption - a fortunate circumstance, because it means that the effect of endogenous capital is not confounded by differences (under taxes and quotas) in strategic interactions. Both the information constrained optimal tax and quota are subgame perfect. Moreover, Proposition 1 enables us to obtain this equilibrium by solving the auxiliary control problem introduced in Sect. 5.2, instead of solving a dynamic game.

The representative firm's benefit function is

$$
B\left(K_{t-1}, \theta_{t}, x_{t}\right)=f_{0}+\left(f_{1}+\psi \theta_{t}\right) K_{t-1}-\frac{f_{2}}{2} K_{t-1}^{2}+\left(a-\phi K_{t-1}+\theta_{t}\right) x_{t}-\frac{b}{2} x_{t}^{2}
$$

with $f_{1}>0, f_{2}>0, b>0, \psi \geq 0, \phi \geq 0$. The function $B(\cdot)$ (which includes the rental cost of capital) satisfies the separability condition. The cost of changing the level of capital is ${ }^{7}$

$$
C\left(I_{t}\right)=\frac{d}{2}\left(I_{t}\right)^{2}, \quad d>0 .
$$

Environmental damages are also quadratic:

$$
D\left(S_{t-1}\right)=\frac{g}{2}\left(S_{t-1}-\bar{S}\right)^{2}
$$

where $\bar{S}$ is the stock level that minimizes damages.

The following remark collects a number of useful facts about the comparison of policies. These results will be obvious to readers familiar with the linear-quadratic control problem, so we state them without proof:

\footnotetext{
7 We can replace the investment cost function with a quadratic function of net rather than gross investment, so that adjustment costs are zero in the steady state. This slightly more plausible model does not lead to any interesting changes in analysis below. However, it complicates the problem of calibrating the model. Therefore we discuss only the model in which adjustment cost depends on gross investment.
} 
Remark 5 In this linear-quadratic model with additive errors, the Principle of Certainty Equivalence holds. The expected trajectories of all stock and flow variables are the same under taxes and quotas. The higher moments of these trajectories differ under the two policies. Neither the policy ranking nor the magnitude of the payoff difference depends on the information state $\left(K_{t-1}, S_{t-1}, \theta_{t-1}\right)$. The magnitude (but not the sign) of the difference in payoffs depends on the variance of cost, $\sigma_{\mu}^{2}$.

\subsection{Regulated emissions and investment}

For the linear-quadratic model, we obtain an explicit equation for the emissions rule (Eq. 15) under taxes:

$$
x_{t}^{*}=e_{t}-\frac{\phi}{b} K_{t-1}+\frac{\theta_{t}}{b} ; \quad e_{t} \equiv \frac{a-p_{t}}{b} .
$$

A higher cost realization increases current emissions, and a higher tax or a higher stock of abatement capital decreases emissions.

Using standard methods (e.g., Chapter 14 of Sargent 1987) we can solve the firm's Euler equation (16) under taxes and (18) under quotas) to write current investment as a linear function of current capital $\left(K_{t-1}\right)$ and the firm's expectations of the future cost variables and policies (taxes or quotas). The optimal investment under emissions taxes is

$$
\begin{aligned}
I_{t}^{*}= & \frac{\lambda \beta f_{1}}{d \delta(1-\lambda \beta)}+(\lambda-\delta) K_{t-1} \\
& +\frac{\lambda \beta}{d \delta} E_{t}\left[\left(\psi-\frac{\phi}{b}\right) \sum_{j=0}^{\infty}(\lambda \beta)^{j} \theta_{t+1+j}-\phi \sum_{j=0}^{\infty}(\lambda \beta)^{j} e_{t+1+j}\right] .
\end{aligned}
$$

where $0<\lambda<1$ is the smaller root of the quadratic equation $\lambda^{2}+\frac{h}{\beta} \lambda+\frac{1}{\beta}=0$ and $h \equiv-\left[\frac{1}{\delta}+\frac{\beta}{d \delta}\left(f_{2}-\frac{\phi^{2}}{b}\right)+\beta \delta\right]$. A lower expected future tax (i.e., a higher value of $e_{t+j}$ ) decreases current investment. A higher expected future cost shock increases (decreases) current investment if $\psi-\frac{\phi}{b}$ is positive (negative). Since $B_{K \theta}=\psi>0$, a higher expected cost shock increases the expected marginal benefit of capital —and thus increases the marginal shadow value of capital. This effect encourages investment. However, a higher expected cost shock increases expected emissions, reducing the expected marginal benefit of capital $\left(B_{x K}=-\phi<0\right)$ and discouraging investment. These offsetting effects are exactly balanced if $\psi=\frac{\phi}{b}$, in which case the cost shock has no effect on investment, under emissions taxes. 
The optimal investment under emissions quotas is ${ }^{8}$

$$
\begin{aligned}
I_{t}^{*}= & \frac{\mu \beta f_{1}}{d \delta(1-\mu \beta)}+(\mu-\delta) K_{t-1} \\
& +\frac{\mu \beta}{d \delta} E_{t}\left[\psi \sum_{j=0}^{\infty}(\mu \beta)^{j} \theta_{t+1+j}-\phi \sum_{j=0}^{\infty}(\mu \beta)^{j} x_{t+1+j}\right] .
\end{aligned}
$$

where $0<\mu<1$ is the smaller root of the quadratic equation $\mu^{2}+\frac{w}{\beta} \mu+\frac{1}{\beta}=0$ and $w \equiv-\left(\frac{1}{\delta}+\frac{\beta f_{2}}{d \delta}+\beta \delta\right)$. Higher expected quotas decrease investment, and higher expected cost shocks increase investment. With quotas, cost shocks have an unambiguous effect, because the firm treats future emissions quotas as exogenous.

\subsection{A limiting case: flow externality}

If $\Delta=0$ all of the pollution stock decays in a single period, and the model collapses to the case of a flow externality. In this case, emissions in the current period cause damages only in the next period: $D\left(S_{t-1}\right)=D\left(x_{t-1}\right) .{ }^{9}$ By defining $\tilde{D}\left(x_{t}\right)=\beta D\left(x_{t}\right)$ we can write the difference between the benefits and costs of current emissions as $B\left(K_{t-1}, \theta_{t}, x_{t}\right)-\tilde{D}\left(x_{t}\right)$. This simplification eliminates a state variable $(S)$, making it possible to obtain some analytic results. We can solve the dynamic programming equations under taxes and quotas and compare the payoffs.

We show that in two cases, the policy ranking does not depend on the parameters associated with abatement capital: (1) $\rho=0$; or (2) $\rho \neq 0$ and $\psi \neq 0$. If neither of these two conditions hold, so that $\rho \neq 0$ and $\psi=0$, the policy ranking does depend on the parameters associated with abatement costs.

If $\rho=0$, or if $\rho \neq 0$ and $\psi \neq 0$, the payoff difference under taxes and quotas, is

$$
\mathcal{J}^{T}-\mathcal{J}^{Q}=\frac{\sigma_{\mu}^{2}}{2 b(1-\beta)}\left(1-\frac{\beta g}{b}\right) .
$$

This expression reproduces a result in Weitzman (1974)'s static model and in two dynamic models (Hoel and Karp 2002; Karp and Zhang 2005).

If $\rho \neq 0$ and $\psi=0$, the payoff difference equals

$$
\mathcal{J}^{T}-\mathcal{J}^{Q}=\frac{\sigma_{u}^{2}}{2 b(1-\beta)}\left[\Gamma+\left(1-\frac{\beta g}{b}\right)\right] .
$$

The function $\Gamma>0$ depends on $f_{2}, d$ and $\delta$ (among other parameters).

\footnotetext{
${ }^{8}$ An algebraic proof confirms that expectated investment is the same under the rules given by Eqs. (27) and (28) —as Remark 5 states they must be.

9 The specialization in this section simplifies the stock pollution problem, and it is also of independent interest, because it shows how to compare taxes and quotas for a flow pollutant when abatement costs are endogenous.
} 
We summarize the implications of these expressions in the following:

Remark 6 For a flow pollutant $(\Delta=0$ ): (i) If (a) $\rho=0$, or if (b) $\rho \neq 0$ and $\psi \neq 0$ ), the policy ranking depends only on the relative slopes (appropriately discounted) of the marginal benefit and damage functions. (ii) When neither conditions (a) or (b) in part (i) hold the policy ranking also depends on the parameters associated with abatement capital.

The next section considers the problem of a stock-related pollutant with $\rho \neq 0$ and $\psi \neq 0$; there the policy ranking does depend on the parameters associated with abatement capital-in contrast to Remark6.i. Here we explain why stock and flow pollutants have this qualitative difference.

As Remark 5 notes, the expected levels of emissions and of investment are the same under taxes and quotas. The first-order condition for investment (using Eqs. 19 or 23) is

$$
-C_{I}\left(I_{t}, K_{t-1}\right)+\beta \mathcal{J}_{K}^{i}\left(K_{t}, S_{t}, \theta_{t}\right)=0, \quad i=T, Q
$$

The linear-quadratic structure with additive uncertainty implies that $\mathcal{J}_{K}^{T}\left(K_{t}, S_{t}, \theta_{t}\right) \equiv$ $\mathcal{J}_{K}^{Q}\left(K_{t}, S_{t}, \theta_{t}\right)$ : the shadow value of capital and, therefore, the investment rules under taxes and quotas, conditional on $\left(K_{t-1}, S_{t}, \theta_{t}\right)$, are identical.

For a stock pollutant, $\mathcal{J}_{K, S}^{i} \neq 0$, so investment at time $t$ depends on the pollution stock at the beginning of the next period, $S_{t}$. That pollution stock depends on current emissions; therefore, emissions in period $t$ affect investment in period $t$. Conditional on the regulator's information at the beginning of a period, the current level of emissions is random under taxes and is a choice variable under quotas. Therefore, conditional on the information at the beginning of a period, the distribution function for the current level of investment differs under the two policies. The expected payoff difference, therefore, depends on the parameters associated with abatement capital.

In contrast, with a flow pollutant, the current level of emissions has no effect on future payoffs. The shadow value of capital $\mathcal{J}_{K}^{i}$ depends only on $\left(K_{t}, \theta_{t}\right)$. With a flow pollutant, the currentinvestment and currentemissions decisions are decoupled. Therefore, the value to the regulator of the difference in emissions under taxes and quotas does not depend on investment costs.

\section{An application to climate change}

With a stock externality problem such as greenhouse gasses, we have three state variables (greenhouse gasses, the capital stock, and the expected cost shock) and therefore cannot obtain an analytic solution. However, using Proposition 1, it is straightforward to solve the tax and quota problems numerically. The resulting control problem is almost standard, except that new information arrives within a period, so there are two stages of optimization within a period. This fact accounts for the nested maximization in Eqs. (19) and (23). For the linear-quadratic model, we can solve each of these dynamic programming problems by solving a matrix Riccati equation. 
Table 1 The model of global warming

\begin{tabular}{|c|c|}
\hline 1. Pollutant stock growth & $S_{t}-\bar{S}=\Delta\left(S_{t-1}-\bar{S}\right)+x_{t}$. \\
\hline 2. Environmental damage & $D\left(S_{t-1}\right)=\frac{g}{2}\left(S_{t-1}-\bar{S}\right)^{2}$ \\
\hline 3. Abatement capital growth & $K_{t}=\delta K_{t-1}+I_{t}$ \\
\hline 4. Investment cost & $C\left(I_{t}\right)=\frac{d}{2} I_{t}^{2}$ \\
\hline 5. "Business as usual" emissions & $x_{t}^{b}=m_{0}-m_{1} K_{t-1}+\tilde{\theta}_{t}$. \\
\hline 6. Abatement cost & $A\left(x_{t}\right)=\frac{b}{2}\left(x_{t}^{b}-x_{t}\right)^{2}$ \\
\hline \multicolumn{2}{|l|}{ 7. "General" benefit function } \\
\hline \multicolumn{2}{|c|}{$B\left(K_{t-1}, \theta_{t}, x_{t}\right)=f_{0}+\left(f_{1}+\psi \theta_{t}\right) K_{t-1}-\frac{f_{2}}{2} K_{t-1}^{2}+\left(a-\phi K_{t-1}+\theta_{t}\right) x_{t}-\frac{b}{2} x_{t}^{2}$} \\
\hline \multicolumn{2}{|l|}{ Parameter restriction } \\
\hline \multicolumn{2}{|c|}{$0 \leq \Delta \leq 1, \quad g>0, \quad 0 \leq \delta \leq 1, \quad d>0, m_{0}>0, m_{1} \geq 0, \quad b>0$} \\
\hline \multicolumn{2}{|c|}{$\theta_{t}=b \tilde{\theta}_{t}, f_{0}=-\frac{b}{2} m_{0}^{2}, f_{1}=b m_{0} m_{1}, f_{2}=b m_{1}^{2}, a=b m_{0}, \phi=b m_{1}$, and $\psi=\frac{\phi}{b}=m_{1}$. } \\
\hline
\end{tabular}

\subsection{Model calibration}

Table 1 describes the model. In order to calibrate the general linear-quadratic model described in the previous section, we assume that benefits are equal to the value of abatement cost that the firm avoids by increasing emissions. Abatement costs are a quadratic function of abatement, $x_{t}^{b}-x_{t}$ (row 6), where the BAU emissions $x_{t}^{b}$ is a decreasing linear function of abatement capital (row 5). A higher level of abatement capital makes it cheaper to reduce emissions, and also decreases the marginal abatement costs. The cost variable $\tilde{\theta}$ (which is proportional to the random variable $\theta$ used above) changes the level of BAU emissions and therefore changes marginal abatement costs. Row 7 of Table 1 repeats the general linear-quadratic model; the final row gives the parameter restrictions under which this general model reproduces the special model described in the rows two to six of the table. ${ }^{10}$ If $m_{1}=0$, capital does not affect abatement costs. This limiting case reproduces previous linear-quadratic models of a stock pollutant (Karp and Zhang 2005)

Table 2 lists baseline parameter values. In presenting the simulation results, we use the parameter $\pi$, defined as the percentage loss in Gross World Product due to a doubling of greenhouse gasses. This parameter is linearly related to $g$, the slope of marginal damages. Our baseline parameters assume that $\pi=1.33$, an estimate that has been widely used. For comparison, we also discuss results when $\pi=3.6$ (the average of expert opinions, reported in Nordhaus 1994a) and $\pi=21$ (the maximum of these expert opinions).

Appendix 3 explains our calibration of the abatement costs (rows 3-6 of Table 1). Our companion paper (Karp and Zhang 2006) ${ }^{11}$ describes the calibration of the growth

\footnotetext{
10 We ignore the effect of $\tilde{\theta}$ on the constant term since the constant has no effect on the regulator's control.

11 That paper studies the problem in which the regulator learns about the relation between pollution stocks and environmental damages; there we ignore abatement capital. Since performing this calibration, more
} 
Table 2 Parameter values for the baseline model

\begin{tabular}{|c|c|c|}
\hline Parameter & Note & Value \\
\hline$\beta$ & A continuous discount rate of $5 \%$ & 0.9512 \\
\hline$\Delta$ & Pollutant stock persistence & 0.9917 \\
\hline$\delta$ & Capital stock persistence & 0.85 \\
\hline$\pi$ & The percentage loss in GWP from doubling $\bar{S}$ & 1.33 \\
\hline$g$ & $\begin{array}{l}\text { Slope of the marginal damage billion } \\
\$ /(\text { billion tons of carbon })^{2}\end{array}$ & 0.0022 \\
\hline$b$ & $\begin{array}{l}\text { Slope of the marginal abatement cost, } \\
\text { billion } \$ /(\text { billion tons of carbon })^{2}\end{array}$ & 26.992 \\
\hline$d$ & Slope of the marginal investment cost, billion $\$$ & 703.31 \\
\hline$m_{0}$ & $\begin{array}{l}\text { Intercept of the BAU emissions, } \\
\text { billion tons of carbon }\end{array}$ & 12.466 \\
\hline$m_{1}$ & $\begin{array}{l}\text { Slope of the BAU emissions, (billion } \\
\text { tons of carbon)/(billion \$) }\end{array}$ & 0.7266 \\
\hline$\rho$ & Cost correlation coefficient & 0.90 \\
\hline$\sigma_{\mu}$ & $\begin{array}{l}\text { Standard deviation of cost shock, } \\
\$ /(\text { ton of carbon })\end{array}$ & 1.7275 \\
\hline$x_{0}^{b}$ & $\begin{array}{l}\text { Current } \mathrm{CO}_{2} \text { emissions into the } \\
\text { atmosphere billion tons of carbon }\end{array}$ & 5.20 \\
\hline $\bar{S}$ & Preindustrial stock, billion tons of carbon & 590 \\
\hline$S_{-1}$ & Current pollutant stock, billion tons of carbon & 781 \\
\hline$K_{-1}$ & Initial capital stock, billion \$ & 10 \\
\hline
\end{tabular}

and damage functions (rows 1 and 2 of Table 1) and of the equation for the random shock (Eq. 12).

\subsection{Numerical results}

We begin by summarizing results from earlier static and dynamic models that exclude abatement capital. We then discuss new results - those directly related to abatement capital.

\subsubsection{Previous results}

Previous papers study the relation between the policy ranking and parameters in the linear-quadratic model with additive errors (Hoel and Karp 2002; Newell and Pizer 2003; Karp and Zhang 2005). Those papers show that the difference in payoffs under optimal taxes and quotas, $\mathcal{J}^{T}-\mathcal{J}^{Q}$, is decreasing in $\frac{g}{b}$. The intuition is the same as in Weitzman (1974)'s static model. A larger value of $g$ means that damages are more convex in $S$. In view of Jensen's inequality, as damages become more convex it becomes more important to control emissions exactly (as under a quota) rather than

Footnote 11 continued

recent estimates of climate-related damage have been published (including Stern 2007; Intergovernmental Panel on Climate Change 2007) but these are within the range of estimates in our calibration. For this reason, and in order for the results here to be comparable to those in our earlier paper, we use the same calibration. 
to choose only the expected value of emissions (as under a tax). A higher value of $b$ makes it more important for the firm to be able to respond to changes in the cost variable by changing emissions. It is able to respond under a tax but not under a quota.

There is a critical value of $\frac{g}{b}$ above which quotas are preferred. This critical value is decreasing in both $\beta$ and $\Delta$. When more weight is put on future costs and benefits (higher $\beta$ ), or when the stock is more persistent (higher $\Delta$ ), it is more important to control the exact level of emissions (as under quotas) rather than the first moment of emissions (as under taxes).

The previous papers calibrate models using parameter values that are consistent with published estimates of the abatement costs and environmental damages associated with greenhouse gasses. These studies find that taxes dominate quotas for the control of greenhouse gasses.

These qualitative results also hold for our parameterization of the model with endogenous abatement capital. This robustness is worth noting, but our analysis adds nothing to the intuition for these results, and therefore we do not discuss them further. Instead, we emphasize the comparative statics and dynamics associated with endogenous abatement costs.

\subsubsection{The role of abatement capital}

There are three important parameters related to abatement capital: $\delta$ (capital stock persistence), $d$ (slope of marginal investment cost), and $m_{1}$ (marginal effect of capital on BAU emissions) We consider the first two briefly, and then concentrate on the third. In all cases, we perform the obvious experiment of varying one of these parameters, holding all others constant. This experiment has a shortcoming that we discuss later, where we consider a second type of experiment.

We explained why a more durable pollution stock (higher $\Delta$ ) decreases the preference for taxes. However, a more durable capital stock (higher $\delta$ ) increases the preference for taxes. Under taxes, the firm responds to a cost shock by changing the level of emissions. For $\rho \neq 0,{ }^{12}$ the firm responds to a cost shock by changing the level of investment, thereby changing the future level of capital under both taxes and quotas. The adjustment mechanism via capital provides a partial substitute for the inability to change emissions under quotas. A large value of $\delta$ means that current investment has long-lasting effects, tending to make capital less flexible. The decreased flexibility associated with larger values of $\delta$ increases the value of being able to respond to the cost shock by changing emissions. A larger value of $\delta$ therefore increases the advantage of taxes.

A lower value of $m_{1}$ (a decrease in the marginal effect of capital on BAU emissions) or a larger value of $d$ (an increase in the adjustment cost for abatement capital), favors quotas. Figure 1 shows the relation between the difference in payoffs (the value of using taxes minus the value of using quotas) and the parameters $d$ and $m_{1}$ for three values of $\pi$, holding all other parameters constant. (Recall that $\pi$ is the percentage loss

\footnotetext{
12 If $\rho=0$, the current cost shock provides no information about the future cost shocks. Since current investment reduces abatement costs only in future periods, the firm's investment does not depend on the current cost shock if $\rho=0$.
} 

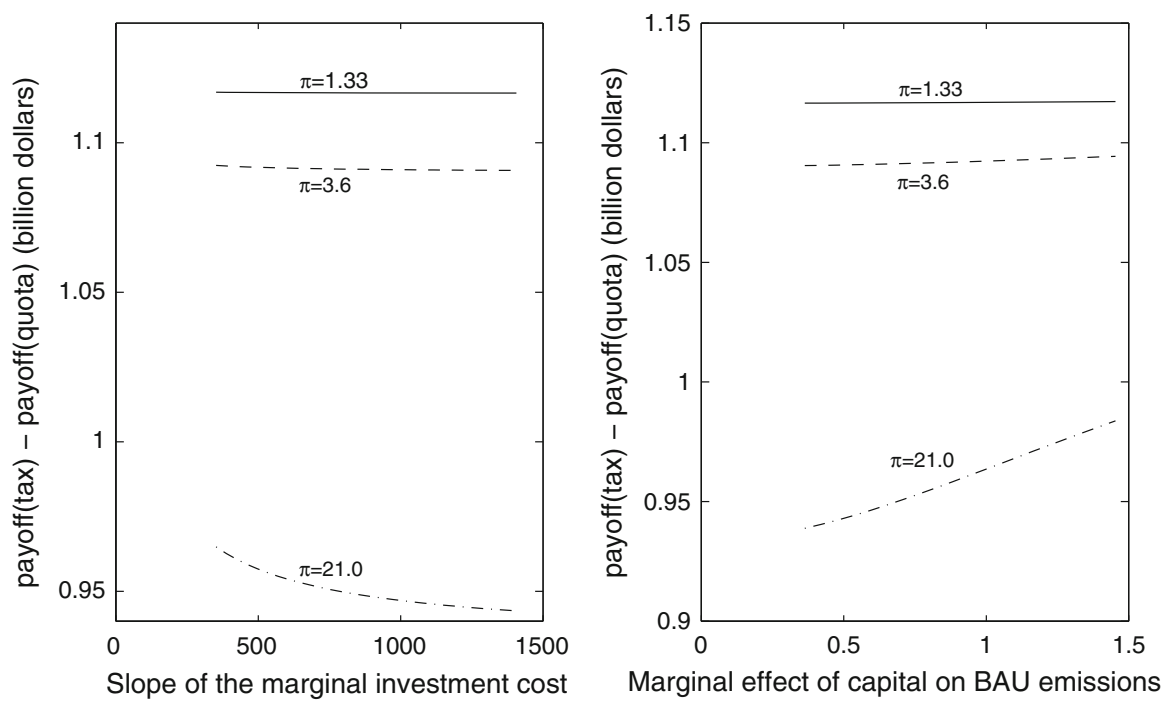

Fig. 1 Dependence of expected payoff difference on cost-related parameters

in global world product due to a doubling of greenhouse gasses.) When environmental damages are moderate ( $\pi=1.33$ or $\pi=3.6$ ) the difference in payoffs is insensitive to changes in $d$ and $m_{1}$; for large environmental damages $(\pi=21)$ the change in either parameter has a noticeable affect on the payoff difference. Previous linear-quadratic models that do not include investment capital are a special case of the model here, obtained by letting $d \rightarrow \infty$ or $m_{1} \rightarrow 0$. Those models tend to understate (slightly) the advantage of using taxes.

As $d$ increases, capital increasingly resembles a fixed input; as $m_{1}$ decreases, abatement capital has less effect on the marginal benefit of pollution. A larger value of $d$ or a smaller value of $m_{1}$ both imply less flexibility of marginal abatement costs. This diminished flexibility favors quotas, just as does the diminished flexibility in marginal abatement costs associated with a smaller value of $b$ (the slope of $B_{x}$ ).

In all cases, the present discounted value of the payoff difference under taxes and quotas is approximately 1 billion dollars, implying an annualized cost of about 50 million dollars. Our parameterization of abatement costs assumes that the annualized cost of stabilizing emissions is about 1 percent of income, or 290 billion dollars. Thus, the payoff difference of the two policies is less than 0.02 of the estimated costs of stabilizing emissions.

The small difference in the expected payoffs may be due largely to the Principle of Certainty Equivalence, mentioned in Sect. 5: the expected stock trajectories are identical under taxes and quotas-only higher moments differ. Uncertainty in our calibrated model (but not in the general formulation) arises only because BAU emissions are uncertain. Given the (small) magnitude of this particular type of uncertainty, the higher moments of stocks simply are not very important. Models that do not satisfy the Principle of Certainty Equivalence find a larger payoff difference under taxes and quotas (Pizer 1999; Hoel and Karp 2001). 
The relations between the equilibrium decision rules and levels of the state variables are as expected. The optimal quota (which equals the expected level of emissions under the optimal tax) decreases with the level of pollution and with the capital stock and increases with the lagged cost shock (for $\rho>0$, as in our calibration). Equilibrium investment is an increasing function of the stock of pollution and a decreasing function of capital stock. Firms understand that a higher pollution stock will lead to lower future equilibrium emissions, increasing the marginal value of investment. A higher aggregate capital stock encourages the regulator to reduce future emissions, increasing the value of investment. However, the representative firm's level of capital equals the aggregate level. For a given quota or tax, a higher capital stock reduces the marginal value of investment. The net effect of higher capital stocks is to reduce investment.

As we mentioned above, the comparative dynamics associated with a change in a single parameter value might be misleading. For example, when we decrease $m_{1}$ holding other parameters constant, we change the BAU level of emissions and the abatement costs associated with a particular emissions trajectory, in addition to changing the marginal effect of capital on abatement costs. Here we consider a slightly different experiment: When we vary $m_{1}$ we make offsetting changes in $m_{0}$ in order to maintain current BAU emissions at 5.2, and we require that the year 2100 BAU emissions are consistent with a particular IPCC scenario.

Our baseline calibration $\left(m_{1}=0.7266\right)$ makes our model consistent with the IPCC

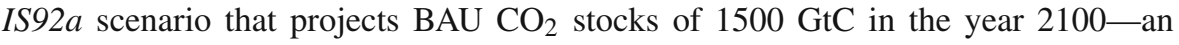
approximate doubling of stocks relative to pre-industrial levels. For comparison we also choose parameters that are consistent with the IS92cscenario of a $35 \%$ increase in $\mathrm{CO}_{2}$ concentration $\left(m_{1}=0.0416\right)$ and with the $I S 92 e$ scenario of a 170 increase in $\mathrm{CO}_{2}$ concentration $\left(m_{1}=1.6622\right)$.

Figure 2 graphs optimal abatement levels, i.e., the difference in the BAU and the optimal levels of emissions (the left panel) and the difference between BAU and the regulated pollution stock (the right panel), as a function of time. The three graphs in each panel correspond to the three values of $m_{1}$. In all cases, abatement increases over time. Both the level and the change over time of abatement is greatest when abatement capital has a large effect on marginal abatement costs $\left(m_{1}\right.$ is large). This result is further evidence that the consideration of endogenous investment in abatement capital increases the optimal level of abatement.

\section{Discussion and conclusion}

The previous literature that compares taxes and quotas assumes that firms solve a sequence of static problems. Our paper recognizes that firms also make investment decisions which affect their future abatement costs. The value of this investment depends on the severity of future environmental restrictions, so the policymaker might have an incentive to announce future environmental policies in order to influence current investment. When this incentive arises, the firms' investment decisions are not constrained optimal, so the regulator would increase welfare if he were able to use an investment tax/subsidy together with the emissions policy. We showed that for general functional forms, when the regulator uses a quota (cap and trade), the competitive 

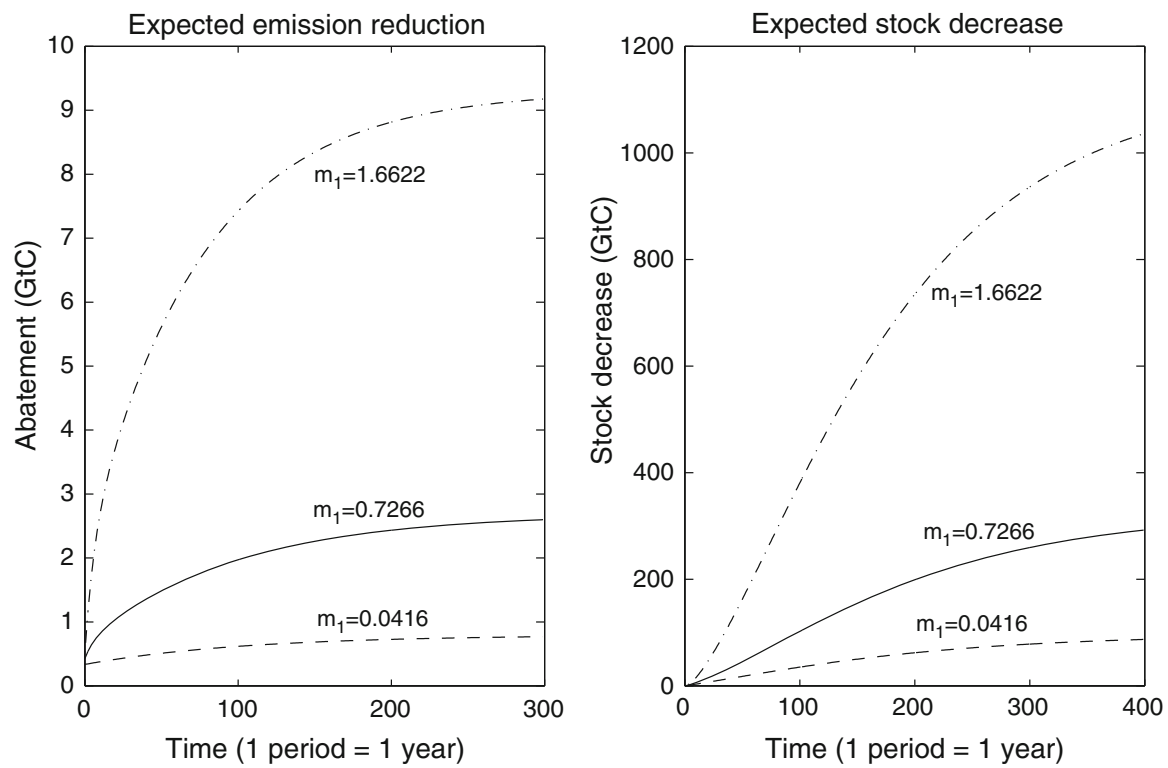

Fig. 2 Changes in expected pollution flows and stocks relative to BAU levels

firms' investment policy is information-constrained efficient. In contrast, for general functional forms, when the regulator uses an emissions tax, the firms' investment policy is not information-constrained efficient. In this sense, there is an advantage to quotas, relative to emissions taxes, that had not previously been recognized.

This particular advantage disappears under a "separability condition" on the primitive functions. The linear-quadratic model, generalized to include endogenous investment, satisfies this condition. Using a calibrated model and a numerical solution, we found that making capital more durable or more effective in reducing the cost of abatement, or reducing the marginal adjustment cost of capital, all favor the use of taxes rather than quotas. These numerical results and the previously described analytic result lead to a mixed message for the comparison of policies. Within the functional assumptions that most previous studies have used, we find that the inclusion of endogenous investment increases the advantage of taxes. However, for more general functional forms, quotas have an entirely different type of advantage. We do not know anything about the magnitude of the latter advantage; its measurement would require a more complicated (i.e., non-linear-quadratic) model, which presents problems of calibration, and it would also require the solution to a dynamic game rather than an optimization problem.

We close by discussing several other views of the relative efficiency of taxes and quotas. One view is that the risk of extreme environmental damages, associated with high GHG stocks, means that over some range damages are likely to be very convex in stocks, i.e., the slope of marginal damages is actually very large. In addition, over a long enough time span, given the opportunities for the development and adoption of new technologies, the marginal abatement cost curve is actually rather flat. Based on these (in our view, plausible) observations, and reasoning from the standard static 
model, Dietz and Stern (2007) conclude that quantity restrictions are more efficient than taxes for climate policy. We have three reasons for doubting this conclusion. First, the use of the static framework (or the open loop assumption in a dynamic setting) is not appropriate for studying climate policy, because the current policymaker cannot choose policy levels decades into the future. More rapid adjustment of policy, i.e., a decrease in the length of period between policy adjustments, favors the use of taxes. Second, even if the possibility of extreme events makes the marginal damage function much steeper than current estimates suggest, the magnitude of the slope of damages would have to be implausibly large to favor quotas. (Hoel and Karp (2002) demonstrate both of these claims.) Third, the current paper shows that endogenous investment in abatement capital is likely to increase the advantage of taxes, given the linear-quadratic framework.

A second view, which we have heard propounded orally but not in writing, is that the existing models inaccurately describe the abatement problem and are, therefore, simply inappropriate for comparing policies. The objection is that firms will first exhaust the cheapest abatement opportunities; once these are used, they are unavailable in the future. There are (at least) two ways to respond to this objection. First, a stationary upward sloping marginal abatement cost curve (used in most previous analyses) is obviously consistent with the claim that firms first use the cheapest way of reducing emissions, and then use more expensive means when regulation becomes stricter. However, because abatement is a flow decision, the fact that the cheap abatement opportunities were used early in the program does not mean that they are unavailable later in the program. The firms move up their marginal abatement curves as the policy becomes stricter. A second response interprets the objection as a call to use a model in which abatement is a stock rather than a flow decision-specifically, a model with endogenous investment in abatement capital, in which there is a sequence of increasingly expensive technologies that reduce emissions. It would be fairly straightforward to produce that kind of model, using a slight modification of the model in this paper. We assumed that the cost of investment is a function of gross investment. To address the objection, we could modify the cost function so that the cost of an additional unit of capital increases with the current level of capital. With this formulation, the firms's level of capital is a proxy for it's stage of technology. Because it first adopts the cheapest (most efficient) technologies, it becomes increasingly expensive to make further reductions in abatement costs. It is not clear how this change affects the policy ranking.

There are several other model variations that would address other interesting questions. For example, network externalities may cause the productivity of a firm's capital to increase with the level of aggregate capital. Also, if we think of investment as being R\&D rather than the installation of new capital, there are likely to be important spillovers. At least in the linear-quadratic framework, it would be straightforward to include such spillovers. There may be intra-firm increasing returns to scale. There might also be learning by doing, so that an increase in cumulative abatement decreases abatement costs. The inclusion of intertemporal trade (banking and borrowing) under quantity restrictions would be even more interesting. Because GHGs are a stock pollutant, the stream of damages can be sensitive to the cumulative emissions 
over a long period of time without being sensitive to the precise timing of emissions. Intertemporal trading allows firms to optimally allocate over time a given cumulative level of emissions. The introduction of banking and borrowing (under the quantity restriction) would likely significantly erode the advantage of taxes. The effect of banking and borrowing on the incentive to invest is not clear. These questions, and the model variations that they entail, are the subject of current research.

\section{Appendix}

The Appendix consists of three parts. Part 1 contains the proof of Proposition 1. Part 2 provides the formulae for $\Gamma$ used in Eq. (29). Part 3 contains information calibration information. An additional Appendix, available on request, contains additional information on calibration.

\section{Proof of Proposition 1}

We use $\rrbracket^{j}(\cdot)(j=T, Q)$ to denote the regulator's value function in the dynamic game (where the regulator chooses only an emissions policy), and $\mathcal{J}^{j}(\cdot)(j=T, Q$ ) to denote the regulator's value function in the corresponding auxiliary problem (where the regulator chooses an emissions policy and then chooses investment after observing the current cost variable). We want to find conditions under which the equilibrium capital and pollution stocks are identical in the Markov perfect equilibrium to the game and in the auxiliary problem. Equivalently, we want to find conditions under which the optimal investment tax/subsidy is identically 0 in the auxiliary problem.

(i) Quotas When the regulator uses an emissions quota, the Euler equations for investment in the Markov perfect equilibrium (Eq. 18) and investment in the auxiliary problem (Eq. 21) are identical, as are the corresponding transversality conditions. We need to confirm that the Euler equations for the pollution stock are also identical in the two settings.

In the Markov perfect equilibrium with quotas the regulator solves the following DPE:

$$
\begin{aligned}
\mathbb{J}^{Q}\left(K_{t-1}, S_{t-1}, \theta_{t-1}\right)= & \max _{x_{t}} E_{\theta_{t} \mid \theta_{t-1}}\left\{B\left(K_{t-1}, \theta_{t}, x_{t}\right)-D\left(S_{t-1}\right)\right. \\
& \left.-C\left(I_{t}^{Q}, K_{t-1}\right)+\beta \rrbracket^{Q}\left(\delta K_{t-1}+I_{t}^{Q}, \Delta S_{t-1}+x_{t}, \theta_{t}\right)\right\}
\end{aligned}
$$

subject to the private investment rule $I_{t}^{Q} \equiv I^{Q}\left(K_{t-1}, \theta_{t}, S_{t-1}\right)$, which is independent of the current quota level $x_{t}$. The stochastic Euler equation for pollution stock is:

$$
\begin{aligned}
& E_{\theta_{t} \mid \theta_{t-1}} B_{x}\left(K_{t-1}, \theta_{t}, x_{t}\right)-\beta D^{\prime}\left(\Delta S_{t-1}+x_{t}\right)-\beta \Delta E_{\theta_{t+1} \mid \theta_{t-1}} \\
& \quad B_{x}\left(K_{t}, \theta_{t+1}, x_{t+1}\right)=0 .
\end{aligned}
$$


The transversality condition is

$$
\lim _{T \rightarrow \infty} E_{\theta_{T} \mid \theta_{t-1}}\left\{\beta^{T-t} B_{x}\left(K_{T-1}, \theta_{T}, x_{T}\right) S_{T}\right\}=0 .
$$

A straightforward calculation confirms that the corresponding Euler equation and transversality condition in the auxiliary problem are identical to the last two equations. (To obtain the Euler equation in the auxiliary problem we differentiate the DPE (19) with respect to $S_{t-1}$, using the envelope theorem; we combine the resulting equation with the first-order condition equation (20).)

(ii) Taxes We first consider the equations that determine the evolution of capital stock. Inspection of the Euler equations for capital (Eq. (16) in the Markov perfect equilibrium and Eq. (25) in the auxiliary problem) establishes that these are identical if and only if the function $\tau$, defined as

$$
\tau_{t} \equiv \beta E_{\theta_{t+1} \mid \theta_{t}}\left\{H_{t+1} \frac{\partial \chi_{t+1}}{\partial K_{t}}\right\},
$$

is identically 0 . We therefore find necessary and sufficient conditions for $\tau_{t} \equiv 0$. Note that the assumptions that $B_{x K}<0$ and $B_{K K}<0$ imply that $\frac{\partial \chi_{t+1}}{\partial K_{t}} \neq 0$.

By Lemma 1, the separability condition is equivalent to

Condition 2 (a) $\frac{\partial \chi\left(K_{t-1}, \theta_{t}, p_{t}\right)}{\partial p_{t}}$ is independent of $\theta_{t}$. (b) $\frac{\partial \chi\left(K_{t-1}, \theta_{t}, p_{t}\right)}{\partial K_{t-1}}$ is independent of $\theta_{t}$.

We, therefore, need only show that Condition 2 is necessary and sufficient for $\tau_{t} \equiv 0$. We first consider sufficiency. If Condition (2a) holds, the first-order condition (24) implies

$$
E_{\theta_{t} \mid \theta_{t-1}}\left\{H_{t}\right\}=0, \quad \forall t
$$

If Condition (2b) also holds, we can write $\tau_{t}$ as

$$
\tau_{t} \equiv \beta\left(\frac{\partial \chi_{t+1}}{\partial K_{t}}\right) E_{\theta_{t+1} \mid \theta_{t}}\left\{H_{t+1}\right\} .
$$

Using Eq. (30), the last equality implies that $\tau_{t} \equiv 0$. Clearly the transversality conditions in the two problems are the same.

The necessity of the separability condition follows from the previous argument. If either part of Condition 2 does not hold the function $\tau$ is not identically 0. (Of course the equality $\tau=0$ might hold for some values of the information state, but we need the stronger condition that the equality hold identically, i.e., for all possible values of the information state.)

To complete the proof, we need only check that the Euler equations and transversality conditions for the pollution stock are also the same in the two problems. In the 
Markov perfect equilibrium with taxes, the regulator solves the following DPE:

$$
\begin{aligned}
\mathbb{J}^{T}\left(K_{t-1}, S_{t-1}, \theta_{t-1}\right)= & \max _{p_{t}} E_{\theta_{t} \mid \theta_{t-1}}\left\{B\left(K_{t-1}, \theta_{t}, \chi_{t}\right)-D\left(S_{t-1}\right)-C\left(I_{t}^{T}, K_{t-1}\right)\right. \\
& \left.+\beta J^{T}\left(\delta K_{t-1}+I_{t}^{T}, \Delta S_{t-1}+\chi_{t}, \theta_{t}\right)\right\}
\end{aligned}
$$

subject to emissions $\chi_{t}$ given by Eq. (15), and the private investment rule $I_{t}^{T} \equiv$ $I^{T}\left(K_{t-1}, \theta_{t}, S_{t-1}\right) . I_{t}^{T}$ is independent of the current tax level $p_{t}$ as discussed in Sect. $4 ; \frac{\partial \chi_{t}}{\partial p_{t}}$ is independent of $\theta_{t}$ because of Condition 1 . Thus the first-order condition for the optimal tax is

$$
E_{\theta_{t} \mid \theta_{t-1}}\left\{B_{x}\left[K_{t-1}, \theta_{t}, \chi\left(K_{t-1}, \theta_{t}, p_{t}\right)\right]+\beta \mathbb{J}_{S}^{T}\left[K_{t}, \Delta S_{t-1}+\chi\left(K_{t-1}, \theta_{t}, p_{t}\right), \theta_{t}\right]\right\}=0
$$

Differentiating the DPE (31) with respect to $S_{t-1}$, using the envelope theorem, and combining the resulting equation with the first-order condition (32) gives the stochastic Euler equation for the pollution stock in the dynamic game:

$$
\begin{aligned}
& E_{\theta_{t} \mid \theta_{t-1}}\left\{B_{x}\left[K_{t-1}, \theta_{t}, \chi\left(K_{t-1}, \theta_{t}, p_{t}\right)\right]-\beta D^{\prime}\left[\Delta S_{t-1}+\chi\left(K_{t-1}, \theta_{t}, p_{t}\right)\right]\right\} \\
& -\beta \Delta E_{\theta_{t+1} \mid \theta_{t-1}} B_{x}\left[K_{t}, \theta_{t+1}, \chi\left(K_{t}, \theta_{t+1}, p_{t+1}\right)\right]=0 .
\end{aligned}
$$

The transversality condition is

$$
\lim _{T \rightarrow \infty} E_{\theta_{T} \mid \theta_{t-1}}\left\{\beta^{T-t} B_{x}\left[K_{T-1}, \theta_{T}, \chi\left(K_{T-1}, \theta_{T}, p_{T}\right)\right] S_{T}\right\}=0
$$

Again, it is straightforward to obtain the Euler equation for pollution stocks in the auxiliary problem. We differentiate Eq. (23) with respect to $S_{t-1}$, using the envelope theorem. Combining the resulting equation with the first-order condition (30) leads to the stochastic Euler equation for the pollution stock in the auxiliary problem. This equation is identical to Eqs. (33). The transversality conditions are also the same. QED

\section{Formulae for $\Gamma$}

The function $\Gamma$ used in Eq. (29) is

$$
\Gamma=\frac{\beta^{2} \rho^{2} \phi^{2} \frac{(d-\beta h)}{b\left(1+\frac{\beta g}{b}\right)^{2}(d-\beta h-d \beta \rho)^{2}}+\frac{\beta \rho^{2}}{1+\frac{\beta g}{b}}}{1-\beta \rho^{2}}>0
$$


with

$$
\begin{array}{r}
h=\frac{-\Xi-\sqrt{\Xi^{2}+4 \beta d\left(f_{2}-\frac{\phi^{2}}{b+\beta g}\right)}}{2 \beta}<0 \\
\Xi \equiv\left(f_{2}-\frac{\phi^{2}}{b+\beta g}\right) \beta-d\left(1-\beta \delta^{2}\right)
\end{array}
$$

\section{Calibration of abatement costs and the shock}

We assume that abatement capital depreciates at an annual rate of $16.25 \%$, the mean of capital stock depreciation rates in 14 OECD countries (Cummins et al. 1996). This depreciation rate implies that $\delta=0.85$.

A higher unit of abatement capital decreases the BAU emissions by $m_{1}$ units. When $m_{1}=0$, BAU emissions are constant, and abatement capital has no effect on the marginal benefit of pollution (i.e., on marginal abatement costs). In this special case, the firm's emission decision and investment decision are decoupled, and the firm's capital stock has no effect on the regulator's optimal policy. The restriction $m_{1}=0$ therefore reproduces the linear-quadratic models of global warming in Karp and Zhang (2006).

The dependence of adjustment costs on gross rather than net investment leads to a simple method of calibration. In the absence of additional regulation, i.e., under Business as Usual-firms never invest: $I_{t}^{b}=0, \forall t \geq 0$. If the initial level of abatement capital is positive, the level monotonically decreases over time, so BAU emissions monotonically increase:

$$
K_{t}^{b}=\delta^{t+1} K_{-1}, \quad x_{t}^{b}=m_{0}-m_{1} K_{t-1}^{b}+\tilde{\theta}_{t}=m_{0}-m_{1} \delta^{t} K_{-1}+\tilde{\theta}_{t},
$$

where $K_{-1}>0$ is the abatement capital at the beginning of the initial period $(t=0)$. Our assumptions provide a simple way to include endogenous investment, and also to reproduce the stylized fact that BAU emissions will increase. The model is "incomplete", since it does not explain why $K_{-1}>0$. The expected future BAU atmospheric $\mathrm{CO}_{2}$ stock is:

$$
S_{t}=\Delta^{t+1} S_{-1}-m_{1} K_{-1} \frac{\delta^{t}\left[1-\left(\frac{\Delta}{\delta}\right)^{t+1}\right]}{1-\frac{\Delta}{\delta}}+\left[m_{0}+(1-\Delta) \bar{S}\right] \frac{1-\Delta^{t+1}}{1-\Delta},
$$

where $S_{-1}$ is the pollutant stock at the beginning of the initial period.

The current anthropogenic fluxes of $\mathrm{CO}_{2}$ into the atmosphere is $5.2 \mathrm{GtC}^{13}$ so we set $E x_{0}^{b}=m_{0}-m_{1} K_{-1}=5.2$ to obtain one calibration equation. The IPCC IS92a

\footnotetext{
13 We use "current" to mean the year 2000. The current total anthropogenic $\mathrm{CO}_{2}$ emissions are about 8.12 $\mathrm{GtC}$, which equals the sum of $6.518 \mathrm{GtC}$ of global $\mathrm{CO}_{2}$ emissions from fossil fuel combustion and cement production (Marland et al. 1999) and $1.6 \mathrm{GtC}$ annual average net $\mathrm{CO}_{2}$ emissions from changes in tropical land-use (Intergovernmental Panel on Climate Change 1996). We obtain the current anthropogenic fluxes of $\mathrm{CO}_{2}$ into the atmosphere $5.20 \mathrm{GtC}$ by multiplying the total anthropogenic emissions by 0.64 , the marginal atmospheric retention ratio.
} 
scenario projects $\mathrm{BAU} \mathrm{CO} \mathrm{CO}_{2}$ stocks at $1,500 \mathrm{GtC}$ in 2100 (Intergovernmental Panel on Climate Change 1996), page 23. This estimate, Eq. (34), and the estimate of current atmospheric $\mathrm{CO}_{2}$ concentration at $S_{-1}=781 \mathrm{GtC}$ (Keeling and Whorf 1999), gives a second calibration equation. The two equations imply

$$
m_{0}=12.466, \quad m_{1} K_{-1}=7.2661 \text {. }
$$

We do not have data on abatement capital, so we choose an arbitrary value for $K_{-1} \cdot{ }^{14}$ We set $K_{-1}=10$.

We choose the baseline values of $d$ (the slope of the marginal investment cost) and $b$ (the slope of the marginal abatement cost) to satisfy a scenario in which firms are required to maintain emissions at the current level in each period. Firms begin with the initial abatement capital and solve an infinite horizon investment problem to minimize the present discounted sum of investment and abatement cost under emission stabilization. In order to determine the two unknown parameters, we assume:

- The annualized discounted present value of firms' total (abatement-related) costs is about $1 \%$ of 1998 GWP (Manne and Richels 1992). ${ }^{15}$

- In the steady state the ratio of investment costs to total abatement costs is about 0.5 (Vogan 1991).

These two assumptions lead to the baseline parameter values: $d=703.31$, and $b=$ 26.992.

\section{Calibration material not intended for publication}

Row 1 in Table 1 is pollutant stock growth equation. We measure $\mathrm{S}_{t}$, the $\mathrm{CO}_{2}$ atmospheric concentration, in billions of tons of carbon equivalent (GtC). $\bar{S}$ equals $590 \mathrm{GtC}$, the preindustrial $\mathrm{CO}_{2}$ concentration (Neftel et al. 1999). Let $e_{t}$ be total anthropogenic $\mathrm{CO}_{2}$ emissions in period $t$. The proportion of emissions contributing to the atmospheric stock is estimated at 0.64 (Goulder and Mathai 2000; Nordhaus 1994b). This fraction accounts for oceanic uptake, other terrestrial sinks, and the carbon cycle (Intergovernmental Panel on Climate Change 1996). The linear approximation of the evolution of the atmospheric pollutant stock is

$$
S_{t}-590=\Delta\left(S_{t-1}-590\right)+0.64 e_{t} .
$$

This equation states that 64 of current emissions contribute to atmospheric $\mathrm{CO}_{2}$, and that $\mathrm{CO}_{2}$ stocks in excess of the preindustrial level decays naturally at an annual rate of $1-\Delta$. We take $x_{t} \equiv 0.64 e_{t}$, the anthropogenic fluxes of $\mathrm{CO}_{2}$ into the atmosphere,

\footnotetext{
14 Even for pollution problems that have been studied in more detail, data on abatement capital is difficult or impossible to obtain. For example, Becker and Henderson (1999) note the absence of estimates of abatement capital stocks associated with U.S. air quality regulation.

15 Manne and Richels (1992) estimate that the total global costs of stabilizing $\mathrm{CO}_{2}$ emissions at the 1990 level are about 4,560 billions of 1990 US dollars, or $20.25 \%$ of the 1990 GWP. We take the same percentage loss and use the annualized value $(1-\beta) \times 20.25 \%=1 \%$.
} 
as the control variable. The stock persistence is $\Delta=0.9917$ (an annual decay rate of 0.0083 and a half-life of 83 years) (Goulder and Mathai 2000; Nordhaus 1994b).

We assume that the preindustrial $\mathrm{CO}_{2}$ concentration has zero environmental damage. Damages from higher $\mathrm{CO}_{2}$ concentration are $\frac{g}{2}(S-\bar{S})^{2}$ (row 2 in Table 1). For ease of interpreting the numerical values, we use $\pi$ to denote the percentage loss in GWP (Gross World Product) from a doubling of the preindustrial $\mathrm{CO}_{2}$ concentration. With the 1998 GWP of 29,185 billion dollars (International Monetary Fund 1999) we have

$$
\pi \% \cdot 29185=g / 2 \cdot 590^{2} \Longrightarrow g=0.0017 \pi \text {. }
$$

For example, $\pi=1.33$ which is widely used corresponds to $g=0.0022$. For the sensitivity analysis we consider two other damage parameters, $\pi=3.6$ and $\pi=21.0$, the mean and the maximum of expert opinions.

Using maximum likelihood, we fit the following data generating process for global carbon emissions over the 50-year period 1947-1996 from Marland et al. (1999).

$$
e_{t}=e_{0}+n t+\varepsilon_{t}, \quad \varepsilon_{t}=\rho \varepsilon_{t-1}+v_{t}, \quad v_{t} \sim \operatorname{iid} N\left(0, \sigma_{v}^{2}\right) \text {. }
$$

The estimates are $\rho=0.9$ and $\sigma_{v}=0.1 \mathrm{GtC}$. We convert the emission uncertainty $\sigma_{v}$ into cost uncertainty $\sigma_{\mu}$ by multiplying it by 0.64 (because $x_{t} \equiv 0.64 e_{t}$ ), and then by the slope of marginal abatement $\operatorname{cost} b=26.992$ (because $\theta_{t} \equiv b \tilde{\theta}_{t}$ ). The result is $\sigma_{\mu}=0.1 \times 0.64 \times 26.992=1.7275 \$ /($ ton of carbon $)$.

Open Access This article is distributed under the terms of the Creative Commons Attribution Noncommercial License which permits any noncommercial use, distribution, and reproduction in any medium, provided the original author(s) and source are credited.

\section{References}

Abrego, L., Perroni, C.: Investment subsidies and time-consistent environmental policy. Oxf Econ Pap 54, 617-635 (2002)

Asheim, G., Mitra, T., Tungodden, B.: Sustainable recursive social welfare functions. Econ Theory (2011) Becker, R., Henderson, J.: Costs of air quality regulation. Working paper 7308, National Bureau of Economic Research (1999)

Biglaiser, G., Horowitz, J., Quiggin, J.: Dynamic pollution regulation. J Regul Econ 8, 33-44 (1995)

Buonanno, P., Carraro, C., Galeotti, M.: Endogenous induced technical change and the costs of Kyoto. Fondazione ENI Enrico Mattei Nota di Lavoro, No 64-01 (2001)

Burniaux, J.-M., Martins, J.: Carbon leakages: a general equilibrium view. Econ Theory (2011)

Chichilnisky, G.: Sustainable markets with short sales. Econ Theory (2011)

Chichilnisky, G., Heal, G.: Markets for tradeable $\mathrm{CO}_{2}$ emission quotas: principles and practice. OECD (1995). http://mpra.ub.uni-muenchen.de/8486/1/MPRA_paper_8486.pdf

Chipman, J., Tian, G.: Detrimental externalities, pollution rights, and the "Coase Theorem". Econ Theory (2011)

Cummins, J., Hassett, K., Hubbard, R.: Tax reforms and investment: a cross-country comparison. J Publ Econ 62(1-2), 237-273 (1996)

Dietz, S., Stern, N.: Why economic analysis supports strong action on climate change. Rev Environ Econ Policy 2, 94-113 (2007) 
Dutta, P., Radner, R.: Capital growth in a global warming model: will China and India sign a climate treaty? Econ Theory (2011)

Ellerman, D.: The EU emissions trading scheme: a prototype global system? In: Aldy, J., Stavins, R. (eds.) Post-Kyoto International Climate Policy, pp. 88- 118. Cambridge: Cambridge University Press (2010)

Figuieres, C., Tidball, M.: Sustainable exploitation of a natural resource: a satisfying use of Chichilnisky's criterion. Econ Theory (2011)

Fischer, C., Parry, I., Pizer, W.: Instrument choice for environmental protection when technological innovation is endogenous. J Environ Econ Manage 45, 523-545 (2003)

Gersbach, H., Glazer, A.: Markets and regulatory hold-up problems. J Environ Econ Manage 37, 151164 (1999)

Goulder, L., Schneider, S.: Induced technological change and the attractiveness of $\mathrm{CO}_{2}$ abatement policies. Resource Energy Econ 21, 211-253 (1999)

Goulder, L.H., Mathai, K.: Optimal $\mathrm{CO}_{2}$ abatement in the presence of induced technological. J Environ Econ Manage 39(1), 1-38 (2000)

Hoel, M., Karp, L.: Taxes and quotas for a stock pollutant with multiplicative uncertainty. J Publ Econ 82, 91$114(2001)$

Hoel, M., Karp, L.: Taxes versus quotas for a stock pollutant. Resource Energy Econ 24, 367-384 (2002)

Intergovernmental Panel on Climate Change: In: Houghton, J.T., Filho, L.G. Meira, Callander, B.A., Harris, N., Kattenberg, A., Maskell, K. (eds.) Climate Change 1995: The Science of Climate Change. IPCC, Cambridge (1996)

Intergovernmental Panel on Climate Change: Climate change 2007 (2007). http://www.ipcc.ch/ SPM040507.pdf

International Monetary Fund: World Economic Outlook. (Washington, DC: International Monetary Fund (IMF) 1999)

Jaffe, A., Newell, R., Stavins, R.: Technological change and the environment. In: Maler, K.-G., Vincent, J. (eds.) Handbook of Environmental Economics, vol. 1, pp. 461-516.Amsterdam: NorthHolland (2003)

Judd, K.: Numerical Methods in Economics. Cambridge: MIT Press (1998)

Karp, L.: Correct (and misleading) arguments for using market-based pollution control technologies (2008). http://are.berkeley.edu/karp/marketbasedJuly08.pdf

Karp, L., Lee, I.H.: Time consistent policies. J Econ Theory 112(2), 353-364 (2003)

Karp, L., Zhang, J.: Regulation of a stock pollution with correlated abatement cost. Environ Resource Econ 32, 273-300 (2005)

Karp, L., Zhang, J.: Regulation with anticipated learning about environmental damage. J Environ Econ Manage 51, 259-280 (2006)

Keeling, C., Whorf, T.: Atmospheric $\mathrm{CO}_{2}$ Records from sites in the SIO air sampling network. In: Trends: A Compendium of Data on Global Change. Carbon Dioxide Information Analysis Center, Oak Ridge National Laboratory, U.S. Department of Energy, Oak Ridge, Tennessee (1999)

Kennedy, P., Laplante, B.: Environmental policy and time consistency: emission taxes and emission trading. In: Petrakis, E., Sartzetakis, E., Xepapadeas, A. (eds.) Environmental Regulation and Market Power, pp. 116-144. Cheltenham: Edward Elgar (1999)

Lauwers, L.: Intergenerational equity, efficiency and constructibility. Econ Theory (2011)

Lecocq, F., Hourcade, J.-C.: Unspoken ethical issues in the climate affair: insights from a theoretical analysis of negotiation mandates. Econ Theory (2011)

Malueg, D.: Emission credit trading and the incentive to adopt new pollution abatement technology. J Environ Econ Manage 16, 52-57 (1989)

Manne, A., Richels, R.: Buying Greenhouse Gas Insurance: The Economic Costs of Carbon Dioxide Emission Limits. Cambridge: MIT Press (1992)

Marcet A., Marimon R. (1998) Recursive contracts. Working Paper ECO No.98/37, European University Institute, Florence, Badia Fiesolana, Economics Department

Marland, G., Boden, T., Andres, R., Brenkert, A., Johnston, C.: Global, Regional, and National CO 2 Emissions. In: Trends: A Compendium of Data on Global Change. Carbon Dioxide Information Analysis Center, Oak Ridge National Laboratory, U.S. Department of Energy, Oak Ridge, Tennessee (1999)

Marsiliani, L., Renstrom, T.: Time inconsistency in environmental policy: tax earmarking as a commitement solution. Econ J 110, C123-C128 (2002)

Milliman, S., Prince, R.: Firm incentives to promote technologicalchange in pollution control. J Environ Econ Manage 17, 247-265 (1989) 
Miranda, M.J., Fackler, P.L.: Applied Computational Economics and Finance. Cambridge: MIT Press (2002)

Moledina, A., Polasky, S., Coggins, J., Costello, C.: Dynamic environmental policy with strategic firms: prices vs. quantities. J Environ Econ Manage 45, 356-376 (2003)

Montero, J.: Permits, standards, and technology innovation. J Environ Econ Manage 44, $23-44$ (2002)

Neftel, A., Friedli, H., Moor, E., Lötscher, H., Oeschger, H., Siegenthaler, U., Stauffer, B.: Historical $\mathrm{CO}_{2}$ record from the siple station ice core. In: Trends: A Compendium of Data on Global Change. Carbon Dioxide Information Analysis Center, Oak Ridge National Laboratory, U.S. Department of Energy, Oak Ridge, Tennessee (1999)

Newell, R., Pizer, W.: Regulating stock externalitiues under uncertainty. J Environ Econ Manage 45, 416432 (2003)

Nordhaus, W.: Managing the Global Commons: the Economics of the Greenhouse Effect. Cambridge: MIT Press (1994)

Nordhaus, W.D.: Expert opinion on climate change. Am Sci 82, 45-51

Norhaus, W.: Modeling induced innovation in climate-change policy. Presented at the IIASA Workshop on Induced Technological Change and the Environment, Luxenburg (1999)

Ostrom, E.: Nested externalities and polycnetric institutions:must we wait for global solutions to climate change before taking actions at other scales? Econ Theory (2011)

Pizer, W.: The optimal choice of climate change policy in the presence of uncertainty. Resour Energy Econ 21(3-4), 255-287 (1999)

Pizer, W.: Combining price and quantity controls to mitigate global climate change. J Publ Econ 85, 409434 (2002)

Requate, T.: Incentives to innovate under emissions taxes and tradeable permits. Eur J Polit Econ 14, 139_ 165 (1998)

Requate, T.: Dynamic incentives by environmental policy instruments. Ecol Econ 54, 175-195 (2005)

Requate, T., Unold, W.: Environmental policy incentives to adopt advanced abatement technology: will the true ranking please stand up? Eur Econ Rev 47, 125-146 (2003)

Rezai, A., Foley, D., Taylor, L.: Global warming and economic externalities. Econ Theory (2011)

Sargent, T.J.: Macroeconomic Theory, 2nd edn. San Diego: Academic Press (1987)

Stern, N.: The Economics of Climate Change. London: Cambridge University Press (2007)

Tarui, N., Polasky, S.: Environmental regulation with technology adoption, learning and strategic behavior. J Environ Econ Manage 50, 447-467 (2005)

Tarui, N., Polasky, S.: Environmental regulation in a dynamic model with uncertainty and investment. Presented at NBER Conference (2006)

Vogan, C.: Pollution abatement and control expenditures. Surv Curr Bus 76, 48-67 (1991)

Weitzman, M.: Prices versus quantities. Rev Econ Stud 41(4), 477-491 (1974)

Xie, D.: On time consistency: a technical issue in stackelberg differential games. J Econ Theory 76, 412430 (1997) 